\title{
UNANTICIPATED INFLATION AND THE VALUE OF THE FIRM
}

\author{
Victor L. BERNARD* \\ University of Michigan, Ann Arbor, MI 48109, USA \\ Received April 1983, final version received May 1985
}

Evidence presented here indicates that the relationship between stock returns and unexpected inflation differs systematically across firms. The differences are shown to be consistent with cross-sectional variation in firms' nominal contracts (monetary claims and depreciation tax shields). The differences are also partially explained by proxies for underlying firm characteristics that could ereate interaction between unexpected inflation and operating profitability. Finally. much if not most of the differences appear to arise because unexpected inflation is correlated with changes in expected aggregate real activity, the effects of which tend to vary across firms according to their systematic risk.

\section{Introduction}

Economists have long discussed how unexpected inflation should differentially affect the real wealth of different economic entities [e.g., Keynes (1924), Alchian and Kessel (1959), Feldstein, Green and Sheshinski (1978)]. These differential effects have generally been described as redistributions of wealth due to the revaluation of nominal contracts (i.e., claims to fixed numbers of monetary units), such as fixed-rate debt contracts. However, empirical research to date has failed to detect the redistributive effects of such revaluations on stock prices. ${ }^{1}$ The conclusion of French, Ruback and Schwert (1983) is that the redistributive effects of unexpected inflation are small and relatively unimportant in explaining stock return behavior.

\footnotetext{
*The support of the University of Michigan and the Deloitte, Haskins \& Sells Foundation is gratefully acknowledged. I am greatly indebted to John Long, Robert Stambaugh (a referee) and one anonymous referee, whose suggestions substantively affected both the focus and methods of this study. Thanks are also due to many others whose comments have affected this research. They include participants at the Stanford-Berkeley joint workshop, and workshops at the University of British Columbia, the University of Chicago, Cornell University, the University of Illinois, the University of Michigan, Northwestern University, the University of Rochester, and the Western Finance Association Meetings. Special thanks are due to my dissertation committee and to my colleagues at Michigan. especially Tom Stober. However, any errors remain the responsibility of the author.

${ }^{1}$ The previous empirical investigations include Bradford (1974), Bach and Stephenson (1974), Hong (1977), Dietrich (1981), Mandelker and Rhee (1981), Summers (1981), and French, Ruback and Schwert (1983). In another study restricted to financial institutions, Flannery and James (1984) do find evidence of the revaluation of nominal contracts in stock price behavior.
} 
This paper attempts to identify and measure the sources of the differential effects of unexpected inflation on stock returns. Evidence presented here indicates that statistically significant cross-sectional differences exist in the associations between stock returns and unexpected inflation. The paper then attempts to explain those differences, in terms of the same nominal contracts examined in prior research, and two other factors not previously explored. Specifically, differential associations between stock returns and unexpected inflation are partially attributed to the revaluation of nominal monetary assets and liabilities recorded in corporate balance sheets, and a set of nominal contracts between corporations and the government, consisting of historicalcost-based tax shields. In addition to these variables, the paper introduces (i) a factor designed to capture the differential impact of unexpected inflation on the current and future operating profitability of firms (before interest and depreciation) and (ii) the factor of systematic risk.

The basic conclusion of the empirical tests is that one can explain a significant portion of the differential associations between unexpected inflation and stock returns. However, the explanation includes information not only about the revaluation of direct monetary claims and depreciation tax shields, but about other factors as well. Thus, the relationship between unexpected inflation and the value of the firm cannot be described as a straightforward product of wealth transfers due to nominal contracting effects, as was originally suggested [for example, see Alchian and Kessel (1959)].

Three more specific conclusions are as follows. First, although the effects of the revaluation of monetary claims and tax shields are detected in stock returns, these effects appear to explain less than one-third of the cross-sectional variance in returns associated with unexpected inflation. Furthermore, these effects are not always detected unless other explanatory variables are included in the design. Thus, while nominal contracting effects are larger than could have been inferred on the basis of previous research, they evidently do not play a dominant role in stock price behavior. Nevertheless, the presence of nominal contracting effects suggests that investors are capable of evaluating the impact of inflation upon the real value of debt, contrary to the hypothesis of Modigliani and Cohn (1979).

A second finding is that at least half of the cross-sectional variance in stock returns associated with unexpected inflation can be explained by cross-sectional differences in systematic risk. This would be expected if unexpected inflation, or associated changes in expected inflation, reflect changes in expected aggregate real activity [see Fama (1981) and Geske and Roll (1983)]. Changes in expected real activity would generally have a greater impact on firms with higher systematic risk.

A third finding is that real cash flows from operations for different firms are differentially affected by unexpected inflation. These differential impacts of unexpected inflation upon operating profitability may be caused by differences 
in firms' underlying operating characteristics. Empirical proxies for these underlying characteristics, called 'cash flow response parameters', are shown to explain a portion (but never more than one-sixth) of the cross-sectional variance in stock returns associated with unexpected inflation.

The paper is organized into five sections. Section 2 discusses the magnitude of cross-sectional differences in the associations of stock returns and unexpected inflation, and proposes a model to explain those differences. The data and some measurement issues are examined in section 3. Section 4 discusses the results of empirical tests of the implications of the model. Conclusions are offered in section 5 .

\section{The magnitude and sources of cross-sectional differences among associations of stock returns and unexpected inflation}

\subsection{The magnitude of the cross-sectional differences}

Consider the following regression of real stock returns against unexpected inflation:

$$
\tilde{R}_{j t}=b_{1 j}+b_{2 j t} \tilde{u}_{t}+\tilde{e}_{j t},
$$

where

$\tilde{R}_{j l} \quad=$ real stock return for firm/industry $j$ for period $t$,

$\tilde{u}_{t} \quad=$ unexpected inflation for period $t$,

$\tilde{e}_{j t} \quad=$ disturbance term, assumed properties of which are discussed below, and

$b_{1 j}, b_{2 j t}=$ regression coefficients.

The slope coefficient $b_{2 j t}$ will be referred to as an 'inflation beta'. As indicated by the subscript, the inflation beta may, in general, vary over time. However, when estimated in a simple time series regression, as is done in this section. $b_{2 j t}$ is assumed to be constant, and the time subscript is dropped.

Previous empirical examinations of the redistributional effects of inflation on stock prices can be viewed as attempts to explain at least part of the cross-sectional differences in inflation betas. Since those previous efforts have generally not detected the redistributional effects of inflation in stock returns, it is logical to ask whether differences in the inflation betas (regardless of their sources) are sufficiently large to be empirically detectable.

An assessment of the magnitude of cross-sectional differences in the inflation betas is conducted using quarterly data for 136 firms from 1961 through 1980. (Sample selection procedures are discussed in appendix A; measurement of unexpected inflation is discussed in appendix B.) The sample includes two to ten representatives from each of 27 industries in the following sectors: mining, manufacturing, transportation, utilities, financial, and consumer services. The 
Table 1

Results of tests of hypothesis that 'inflation betas'a are equal across all firms or industries. Data are quarterly observations from 1961:I to 1980:IV.

\begin{tabular}{|c|c|c|c|c|c|}
\hline Test & $\begin{array}{c}\text { Cross-sectional } \\
\text { units }\end{array}$ & $\begin{array}{l}\text { Assumptions } \\
\text { on } \\
\text { covariance } \\
\text { matrix }^{\mathrm{b}}\end{array}$ & $F$-statistic & $\begin{array}{c}\text { Degrees } \\
\text { of } \\
\text { freedom }\end{array}$ & $\begin{array}{c}\text { Significance } \\
\text { level }\end{array}$ \\
\hline (1) & 136 firms & Diagonal & 1.22 & 135,10608 & 0.043 \\
\hline (2) & 27 industries & Diagonal & 1.03 & 26,2106 & 0.427 \\
\hline (3) & 27 industries & Full & 2.70 & 26,2106 & 0.000 \\
\hline
\end{tabular}

"Inflation betas are defined as the coefficients $b_{2 j}$ in the following set of equations:

$$
\tilde{R}_{j t}=b_{1 j}+b_{2,} \tilde{u}_{i}+\tilde{e}_{j t} \text {, }
$$

where $\tilde{R}_{t t}$ is the real stock return for firm/industry $j(j=1,2, \ldots, J)$ for quarter $t$, and $\tilde{u}_{t}$ is the unexpected inflation for quarter $t$.

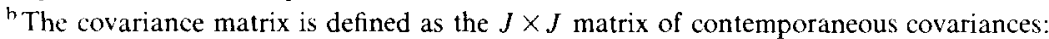

$$
\sigma_{i j}=\operatorname{cov}\left[\tilde{e}_{i t}, \tilde{e}_{j l}\right] \text { for } i=1,2, \ldots, J \text { and } j=1,2, \ldots, J \text {. }
$$

inflation betas for all 136 firms are negative and range from -0.29 to -23.91 . Inflation betas for 116 of 136 firms and 24 of 27 industries are significantly below zero at the 0.05 level. Thus, the negative relation between aggregate stock market returns and unexpected inflation [documented by Fama and Schwert (1977), among others] appears to hold for most, if not all individual stocks as well.

To examine the significance of cross-sectional differences in the inflation betas, a series of standard hypothesis tests of linear restrictions on $b_{2 j}$ are conducted. ${ }^{2}$ In all tests, the null hypothesis is that the true values of $b_{2 j}$ are the same for all $j$. Results of these hypothesis tests are presented in table 1.

The first two tests in table 1 allow for cross-sectional heteroscedasticity in the disturbances, $\tilde{e}_{j l}$, but assume that those disturbances are not contemporaneously correlated. The first test is performed using firm-specific data and permits rejection of the null hypothesis at the 0.05 level. In contrast, when the data are aggregated by industry in the second test, the hypothesis of equal inflation betas across industries cannot be rejected. However, when industry portfolios are used, one can increase efficiency by relaxing the assumption of no contemporaneous correlation in the disturbance terms, and estimate a full residual covariance matrix. ${ }^{3}$ The third test reported in table 1 is based on such a procedure, and the test statistic permits rejection of the hypothesis of equal

\footnotetext{
${ }^{2}$ See Judge, Griffiths, Hill and Lee (1980, sec. 6.1.2, esp. eq. 6.1.13). Schipper and Thompson (1981) present similar evidence for a different period, but add (p. 314) that their tests do not distinguish between the effects of unexpected inflation and shifts in the real rate of interest.

${ }^{3}$ Estimation of a full covariance matrix requires that the number of time series observations exceeds the number of cross-sectional units.
} 
inflation betas across industries, at the 0.0001 level of significance. Thus, significant cross-sectional differences do appear to exist among the associations of unexpected inflation and stock returns. ${ }^{4}$

\subsection{The sources of the cross-sectional differences}

Given that there are significant cross-sectional differences in the associations of stock returns and unexpected inflation, explanations for those differences are now examined. Previous research has attempted to explain the differences as a function of wealth redistribution caused by revaluation of certain nominal contracts [for example, see Bradford (1974), Bach and Stephenson (1974), Hong (1977), Dietrich (1981), Mandelker and Rhee (1981), Summers (1981), French, Ruback and Schwert (1983)]. This section models not only nominal contracting effects, but also other potential sources of cross-sectional variation in the association between stock returns and unexpected inflation.

\subsubsection{Nominal contracting effects}

One set of nominal contracts examined in all prior studies consists of debt and other monetary claims recorded in corporate balance sheets. Such claims include monetary assets (cash, receivables, investments in notes and bonds) and monetary liabilities (current liabilities, debt, and preferred stock). When unexpected inflation causes changes in the real values of monetary assets and liabilities, stock returns of corporations holding such assets and liabilities reflect those changes. If unexpected inflation is positive, firms with a net debtor position should benefit (ceteris paribus) and net creditors should be harmed. Furthermore, the magnitude of the impact on the real value of a firm's common shares should depend on the magnitude of the firm's net monetary position (monetary assets, less monetary liabilities), relative to the value of the firm's common shares. If, in addition, unexpected inflation is accompanied by a change in expected inflation, then the impact on stock prices should also depend on the maturity structure of the firm's monetary accounts, since the values of items of longer maturity would be more sensitive to changes in expected inflation. For this reason, French, Ruback and Schwert (1983) model the impact of unexpected inflation upon stock prices as a function of the magnitude of the net monetary position, segregated into short-term and long-term components. This segregation will be maintained here as well.

\footnotetext{
${ }^{4}$ Inflation betas were also estimated using annual data for 1961-1980. Estimated inflation betas were negative for 133 of 136 firms and for each of the 27 industries, and were significantly negative at the 0.05 level for 92 firms and 20 industries. Results of tests of the significance of cross-sectional differences in inflation betas were similar to those reported, except that tests based on a full residual covariance matrix were not feasible with annual data.
} 
Another set of nominal contracts examined in recent studies consists of depreciation tax shields. Since depreciation tax shields are not adjusted for inflation, they represent a claim by the corporation to deduct a fixed number of dollars from taxable income. Thus, depreciation tax shields represent nominal contacts between corporations and the government. Positive unexpected inflation should cause a reduction in the expected real value of future depreciation tax deductions. The resulting impact on stock prices is analogous to the effect of the revaluation of the net monetary position. ${ }^{5}$

The above discussion suggests that differences among firms' inflation betas could be modeled as functions of differences among firms' short-term monetary positions (STMP), long-term monetary positions ( $L T M P$ ), and the tax basis of firms' depreciable assets $(T A X)$. The following model is employed by French, Ruback and Schwert (1983):

$$
b_{2 j t}=k_{1 j}+k_{2} \frac{S T M P_{j, t-1}}{V_{j, t-1}}+k_{3} \frac{L T M P_{j, t-1}}{V_{j, t-1}}+k_{4} \frac{T A X_{j, t-1}}{V_{j, t-1}},
$$

where $k_{1 j}, k_{2}, k_{3}$, and $k_{4}$ are fixed parameters, and $V_{j, t-1}$ is the value of firm $j$ 's common shares at time $t-1$. STMP, LTMP, and TAX are scaled by the value of common shares, so that all variables are stated in terms of common units of measure. The parameters $k_{1 j}$ are not called for by the theory, but are included by French, Ruback and Schwert, apparently to capture the effects (if any) of omitted variables or measurement errors that vary cross-sectionally but not over time. Substitution of (2) into (1) yields

$$
\begin{aligned}
\tilde{R}_{j t}= & b_{1 j}+k_{1 j} \tilde{u}_{t}+k_{2} \frac{S T M P_{j, t-1}}{V_{j, t-1}} \tilde{u}_{t}+k_{3} \frac{L T M P_{j, t-1}}{V_{j, t-1}} \tilde{u}_{t} \\
& +k_{4} \frac{T A X_{j, t-1}}{V_{j, t-1}} \tilde{u}_{t}+\tilde{e}_{j t} .
\end{aligned}
$$

French, Ruback and Schwert estimate eq. (3) in order to test the "nominal contracting hypothesis'. Under that hypothesis, 'nominal contracting plays a large role in explaining the behavior of stock prices' (p. 71). When STMP and LTMP are defined so as to be positive for net short-term creditors and net long-term creditors, respectively, the nominal contracting hypothesis implies that the coefficients $k_{2}, k_{3}$, and $k_{4}$ in eq. (3) should be negative. Since the

\footnotetext{
${ }^{5}$ If unexpected inflation causes a change in expected inflation, then the impact will depend not only on the magnitude of the tax shields, but also on the timing of future depreciation deductions. However, constraints on data availability have caused previous researchers to assume that variation in the maturity structure of tax shields is small, relative to variation in the magnitudes of those tax shields. That assumption is also adopted here.
} 
estimates of French, Ruback and Schwert are often positive or insignificant, they conclude that the wealth effects caused by revaluation of nominal contracts are small compared with other factors that affect stock values.

The evidence in section 2.1 suggested that the inflation betas $\left(b_{2 j t}\right.$ 's) in eq. (2) differ across firms. When this evidence is combined with the lack of support for the nominal contracting hypothesis, it evokes the following questions. First, what factors, aside from those already tested by French, Ruback and Schwert, might explain differences in the associations of stock returns with unexpected inflation? Second, if such factors could be identified, would an expanded specification of eq. (3) then yield estimates of $k_{2}, k_{3}$, and $k_{4}$ that are consistent with the inverse relation between unexpected inflation and the real value of nominal contracts? Or are the nominal contracting effects so small as to be empirically undetectable, even under a more complete specification?

Two additional factors are now introduced that could potentially explain cross-sectional differences in the association of stock returns with unexpected inflation. The first factor describes the differential impact of unexpected inflation upon real cash flows from operations. The second factor is systematic market risk.

\subsubsection{The impact of unexpected inflation upon cash flows from operations}

To see the relevance of the first additional factor, consider the value of the firm's common shares as the sum of the values of three streams of real (inflation-adjusted) cash flows: (i) cash flows associated with the issue, service, and retirement of monetary claims (net of related tax effects), (ii) cash fiows associated with the depreciation tax deduction, and (iii) cash flows from operations (i.e., income before depreciation and interest), net of related income taxes. Differences across firms in the impact of unexpected inflation upon the first component of cash flows should be captured by the terms $k_{2} S T M P$ and $k_{3} L T M P$ of eq. (2); differences in the impact on the second component of cash flows should be described by the term $k_{4} T A X$. The question that remains, then, is whether unexpected inflation would also affect the value of the third stream of cash flows: those from operations.

The impact of unexpected inflation upon real cash flows from operations is modeled as follows. Let $\mathrm{E}_{t}\left(\tilde{C}_{j \tau}\right)$ represent real (inflation-adjusted) pre-tax cash flows from operations for firm $j$, expected (as of the end of period $t$ ) to be realized in period $\tau(\tau \geq t)$. When quarterly data are considered, expectations about cash flows of period $\tau+4$ are characterized as

$$
\mathrm{E}_{t}\left(\tilde{C}_{j, \tau+4}\right)=\mathrm{E}_{t}\left(\tilde{C}_{j \tau}\right)+d_{j} \text { for } \tau=t, t+1, t+2 \ldots
$$

Eq. (4) assumes that expected cash flows for any future quarter $\tau+4$ arc equal to expected cash flows for quarter $\tau$, plus a drift term, $d_{j}$. Empirical 
support for the reasonableness of this assumption can be found in Foster (1977). ${ }^{6}$ This assumption permits one to write the present value of current and all future cash flows in terms of expected cash flows for only four quarters, $t$ through $t+3$. This is done in eq. (5). In eq. (5), it is assumed that the real one-period discount factor $p_{j}$ (where $p_{j}<1$ ) is the same for each future period, and thus cash flows to be received $\tau-t$ quarters hence are discounted by the factor $p_{j}^{\tau-t}$.

$$
\sum_{\tau=t}^{\alpha} p_{j}^{\tau-t} \mathrm{E}_{t}\left(\tilde{C}_{j \tau}\right)=\left(1-p_{j}^{4}\right)^{-1} \sum_{\tau=t}^{t+3} p_{j}^{\tau-t}\left[\mathrm{E}_{t}\left(\tilde{C}_{j \tau}\right)+D_{j}\right]
$$

where

$p_{j}=$ real one-period discount factor, equal to the reciprocal of one plus the expected real return, and

$D_{j}=d_{j} p_{j}^{4}\left(1-p_{j}^{4}\right)^{-1}$.

Eqs. (4) and (5) above describe expectations at a given point in time. Now consider how those expectations change over time. Changes would be due to unexpected shocks, including unexpected inflation. If unexpected inflation occurs, its impact upon expected real cash flows may vary from firm to firm. In eq. (6), the impact of unexpected inflation of quarter $t\left(\tilde{u}_{t}\right)$ upon expected real cash flows of quarter $\tau$ for firm $j$ is expressed as a function of firm-specific 'cash flow response parameters' $\left(\theta_{j, \tau-t+1}\right)$.

$$
\mathrm{E}_{t}\left(\tilde{C}_{j \tau}\right)=\mathrm{E}_{t-1}\left(\tilde{C}_{j \tau}\right)+\theta_{j, \tau-t+1} \tilde{u}_{t}+z_{j t}^{\tau}, \quad \tau=t, t+1, t+2, \ldots
$$

where $\tilde{z}_{j t}^{\tau}$ is the portion of change in expected cash flows of quarter $\tau$ that is uncorrelated with $\tilde{u}_{i}$.

The cash flow response parameters $\theta_{j, \tau-t+1}$ are assumed to be constant over time, for a given firm. That is, the amount of the change in expected real cash flows, due to a given amount of unexpected inflation, does not vary according

\footnotetext{
${ }^{6}$ Foster (1977) shows that quarterly income series behave differently for different firms. Nevertheless, a naive one-step-ahead forecast of quarter $t$ earnings, equal to earnings of quarter $t-4$ plus a drift term, appeared to approximate the expectations of stock market participants more closely than more sophisticated univariate forecasts, including firm-specific Box-Jenkins forecasts.

The model assumed here to describe the time series behavior of earnings is less restrictive than the naive model studied by Foster. Whereas Foster's naive model assumes that quarter $t-4$ earnings provide efficient forecasts of quarter $t$ earnings as of quarter $t-1$, it is assumed here that such a forecast is efficient only as of quarter $t-4$. In the subsequent quarters $t-3, t-2$ and $t-1$, it is assumed that an efficient forecast of quarter $t$ earnings would include not only earnings of quarter $t-4$, but possibly also unexpected inflation realized since quarter $t-4$. Thus, whereas Foster studied only univariate time series models, earnings are permitted here to follow a bivariate process.
} 
to the period in which the unexpected inflation occurs. However, the change is allowed to vary according to the length of the lag $(\tau-t)$ between the occurrence of the unexpected inflation and the realization of the cash flows.

Eq. (6), in combination with eq. (5), implies that the change in the present value of expected real cash flows, due to shocks of quarter $t$, can be written as

$$
\begin{aligned}
\sum_{\tau=t}^{\infty} p_{j}^{\tau-t}\left[\mathrm{E}_{t}\left(\tilde{C}_{j \tau}\right)-\mathrm{E}_{t-1}\left(\tilde{C}_{j \tau}\right)\right]= & \left(1-p_{j}^{4}\right)^{-1} \sum_{\tau-t}^{t+3} p_{j}^{\tau-t} \theta_{j, \tau-t+1} \tilde{u}_{t} \\
& +\left(1-p_{j}^{4}\right)^{-1} \sum_{\tau=t}^{t+3} p_{j}^{\tau-t} \tilde{z}_{j t}^{\tau} .
\end{aligned}
$$

The impact of unexpected inflation is captured by the first term on the right-hand side of eq. (7). Thus, cross-sectional differences in the impact of unexpected inflation upon expected real cash flows are written as a function of variation in the discount factor $p_{j}$ and only four firm-specific cash flow response parameters, $\theta_{j 1}, \theta_{j 2}, \theta_{j 3}, \theta_{j 4}$.

For purposes of estimation, it will be assumed that cross-sectional differences in the impact of unexpected inflation upon the present valuc of expected cash flows are captured in large part by cross-sectional variation in the cash flow response parameters. That is, variation in the discount factor $p_{i}$ that appears in the first term on the right-hand side of eq. (7) is not measured. Note also that since the object of ultimate concern is the impact of unexpected inflation on after-tax cash flows, the incremental impact on pre-tax cash flows described above should be multiplied by one minus the marginal tax rate, $T$. However, $T$ is assumed constant across firms, so that only the scale of the effect of unexpected inflation is altered. With these simplifications, the first term on the right-hand side of eq. (7) becomes

$$
\begin{aligned}
(1-T)\left(1-p_{j}^{4}\right)^{-1} \sum_{\tau=t}^{t+3} p_{j}^{\tau-t} \theta_{j, \tau-t+1} \tilde{u}_{t} & \cong k_{5} \sum_{\tau=t}^{t+3} \theta_{j, \tau-t+1} \tilde{u}_{t} \\
& \equiv k_{5} \tilde{u}_{t} \sum_{n=1}^{4} \theta_{j n},
\end{aligned}
$$

where $k_{5}$ is a positive scalar and $n=\tau-t+1$.

\footnotetext{
${ }^{7}$ Variation in $p$, could be permitted by allowing the coefficient $k_{5}$ in eq. (8) to vary across $j$ and $n$, and writing that coefficient as $k_{5 / n}$. By focusing only on the cross-sectional variation in the response parameters, the model constrains the coefficient $k_{5 i n}$ to be the same for all values of $j$ and $n$. This approach creates no bias so long as $\left(k_{5, n}-k_{\varsigma}\right) \theta_{j n}$ is not correlated with any of the other variables ultimately to be included in the model. In that case, the estimate of $k_{5}$ will represent a weighted average of the values of $k_{5 / n}$.
} 
The impact of unexpected inflation upon the real value of cash flows from operations, as represented by the term on the extreme right-hand side of eq. (8), will be incorporated as an additional factor to explain the differential associations of stock returns and unexpected inflation.

While we have not yet discussed the specific underlying firm characteristics that cause cross-sectional variation in the cash flow response parameters, it should be noted that those factors are not necessarily distinct in nature from the previously discussed nominal contracting effects. First, cash flows from operations may reflect the revaluation of nominal contracts, such as nominal sales contracts and labor agreements, that are not recorded in corporate balance sheets and would not be captured by STMP or LTMP. Second, cash flows from operations may be affected indirectly by a revaluation of nominal contracts held by customers, such as investments in fixed income streams, or any income tax liabilities that are not indexed. Redistribution of customer wealth would, in general, redistribute the demand for firms' goods and services whenever that demand is income-elastic. Finally, even where explicit nominal contracts do not exist, the real cash flows may be affected by market frictions that cause the firm to maintain some nominal price inflexibility. ${ }^{8}$

\subsubsection{Unexpected inflation, stock returns, and systematic risk}

The factors discussed in the two previous subsections are intended to describe causal links between unexpected inflation and individual stock returns. However, to the extent those factors describe nominal contracting effects, they may be purely redistributive. For that reason, such effects do not play an important role in explanations offered by Fama (1981) or Geske and Roll (1983) for the well-documented negative relation between aggregate stock returns and inflation. ${ }^{9}$ Fama suggests that the negative association between aggregate stock returns and inflation (both expected and unexpected) is spurious. The negative association is proxying for positive associations between stock returns and aggregate real activity, which in turn is negatively correlated with inflation. The latter correlation is explained by a combination of money demand theory and the quantity theory of money. The Geske-Roll view differs, but still focuses on the relationship between aggregate real activity and inflation. Geske and Roll suggest that, as a result of the way the money supply is regulated, stock returns signal changes in real activity that 'cause' (in an econometric sense) changes in expected inflation of the opposite sign. Since

\footnotetext{
${ }^{8}$ For example, Okun (1981, ch. IV) explains how the existence of information acquisition costs on the part of customers can give rise to nominal price inflexibility in certain kinds of product markets.

${ }^{9}$ Geske and Roll (1983, pp. 3-4) review previous research concerning nominal contracting effects, but dismiss the possibility that those effects could explain the negative inflation/stock return relationship observed in the aggregate. Fama (1981) says little about nominal contracting effects, but suggests (p. 553, footnote 3) that the revaluation of historical-cost-based depreciation tax shields has probably been offset (at least in the aggregate) by changes in the tax law, and the deduction of nominal interest expense.
} 
changes in expected inflation are likely to be positively correlated with (and may even induce) unexpected inflation, the Geske-Roll explanation is consistent with a negative correlation between unexpected inflation and aggregate stock returns.

Although both Fama and Geske and Roll are concerned with aggregate stock returns, their theories have implications for the association of inflation and individual stock returns. In their theories, inflation is either a negative proxy for, or a result of, changes in aggregate real activity. Thus, the observed cross-sectional differences in the association between unexpected inflation and individual stock returns would simply reflect cross-sectional differences in the impact of changes in expected real activity. Since, by definition of systematic risk, ${ }^{10}$ expected cross-sectional differences in the impact of fluctuations in aggregate real activity are linear in systematic risk, the differential associations of stock returns and unexpected inflation would also (in part) be linear in systematic risk. Given the negative relation between inflation and aggregate real activity, firms with the highest systematic risk would have returns that are most negatively associated with unexpected inflation.

If 'inflation betas' are indeed inversely related to systematic risk, then estimates of eq. (3), which excludes systematic risk, would be biased in a way that could mask certain nominal contracting effects. For example, since $L T M P$ is defined to be negative for net long-term debtors, firms with the most negative values of LTMP should, ceteris paribus, benefit most from positive unexpected inflation and have the highest inflation betas. But those same large debtors should also tend to have higher systematic risk [Hamada (1969)], which would cause them to have lower inflation betas. If systematic risk is omitted in the specification and $L T M P$ serves partially as a proxy for that omitted factor, the estimated coefficient of $L T M P$ could be biased upward.

\subsubsection{The expanded model}

The discussion above suggests that a more complete specification of eq. (2) would include the cash flow response parameters $\left(\sum_{n} \theta_{j m i}\right)$ and systematic risk $\left(\beta_{j t}\right)$ as additional explanatory factors, as follows:

$$
\begin{aligned}
h_{2, j t}= & k_{1}+k_{2} \frac{S T M P_{j, t-1}}{V_{j, t-1}}+k_{3} \frac{L T M P_{j, t-1}}{V_{j, t-1}}+k_{4} \frac{T A X_{j, t} 1}{V_{j, t-1}} \\
& +k_{5} \frac{\sum_{n} \theta_{j n t}}{V_{j, t-1}}+k_{6} \beta_{j l},
\end{aligned}
$$

\footnotetext{
${ }^{10}$ Systematic risk as used here denotes the sensitivity of individual stock returns to aggregate stock returns, as would be reflected in the slope coefficient of the market model.
} 
where $k_{1}$ through $k_{6}$ are fixed parameters, and all other variables are defined above. ${ }^{11}$

The time subscript $t$ for $\sum_{n} \theta_{j n t}$ and $\beta_{j t}$ is used here to indicate that estimates of those parameters vary by period; values to be used in eq. (9) for period $t$ are estimated while excluding a window of data from periods in and surrounding period $t$. (Details are discussed in section 3 and appendices $A$ and $C$.) Since $\sum_{n} \theta_{j n t}$ and $\beta_{j t}$ are to be estimated out of sample, estimates of the above model will provide a joint test of (i) the explanatory power of $\sum_{n} \theta_{j n t}$ and $\beta_{j t}$, and (ii) stationarity in those parameters. Note also that, whereas the intercept of eq. (2), $k_{1 j}$, is permitted to vary cross-sectionally, the intercept in eq. (9), $k_{1}$, is constrained to be equal for all firms. Since there is no a priori reason to expect $k_{1}$, to vary across firms, that constraint is expected to increase efficiency. ${ }^{12}$ However, empirical estimates of a model that excludes $\sum_{n} \theta_{j n t}$ and $\beta_{j t}$ [as in eq. (2)] will also be estimated; in that case, there is a priori reason to expect that omission of variables could cause cross-sectional differences in the intercept term, and thus, that model will be estimated both with and without the constraint on $k_{1 ;}$.

Substituting eq. (9) into eq. (1), one obtains

$$
\begin{aligned}
\tilde{R}_{j t}= & b_{1 j}+k_{1} \tilde{u}_{t}+k_{2} \frac{S T M P_{j, t-1}}{V_{j, t-1}} \tilde{u}_{t}+k_{3} \frac{L T M P_{j, t-1}}{V_{j, t-1}} \tilde{u}_{t}+k_{4} \frac{T A X_{j, t-1}}{V_{j, t-1}} \tilde{u}_{j} \\
& +k_{5} \frac{\sum_{n} \theta_{j n t}}{V_{j, t-1}} \tilde{u}_{t}+k_{6} \beta_{j t} \tilde{u}_{t}+\tilde{e}_{j t}
\end{aligned}
$$

Eq. (10) serves as the general version of the model to be estimated in the paper. Throughout the remaining discussion, subscripts on the independent variables of eq. (10) are generally suppressed for convenience.

\section{Description of the data}

\subsection{Test sample, test period, and measurement issues}

The empirical tests employ data for 136 firms from 27 industries, as listed in table 2. Data required for the estimation of eq. (10) are available for those

\footnotetext{
${ }^{11}$ Since the cash flow response parameters, like the variables $S T M P, L T M P$, and $T A X$, reflect differences in firm size, the response parameters are scaled in the same manner as STMP, I.TMP, and $T A X$.

${ }^{12}$ In particular, if any of the independent variables in eq. (9) were nearly constant over tims, but variable across firms, they would be nearly collinear with an intercept that was also permitted to vary across firms. The high degree of collinearity would tend to reduce precision in the estimated coefficients. There is no offsetting gain in precision unless variation in the interecpt could capture the effects of otherwise omitted factors.
} 
firms on an annual basis for 1961-1980 and on a quarterly basis for 1966-1980. The primary empirical analysis is based on quarterly data. However, even though the quarterly data provide a larger sample size, it's not clear that quarterly data would provide more powerful tests. The reason is that in quarterly data, measurement error is likely to be a more serious matter for income from operations (needed for estimation of the cash flow response parameters), for inflation adjustments to that income, and for unexpected inflation. ${ }^{13}$ To assess the tradeoff between sample size and measurement error, some supplemental tests employ both annual and quarterly data. However, since the results are usually insensitive to the measurement interval, those based on annual data are discussed only in footnotes.

Data sources and the details of procedures used to measure real (inflationadjusted) cash flows from operations, short-term monetary position ( $S T M P$ ), long-term monetary position (ITMP), the tax basis of depreciable assets $(T A X)$, and systematic risk $(\beta)$ are discussed in appendix $A$. The measure of $S T M P$ used here is the same as that used by French, Ruback and Schwert, but mcasures of LTMP and TAX differ slightly. As measured here, LTMP includes long-term monetary assets, available only through detailed examination of annual reports and 10-K's. In addition, whereas previous researchers relied on Compustat data to approximate the tax basis of depreciable assets, the measure used here was based on a detailed review of the firms' depreciation policies and calculation of the average age of the firms' depreciable assets (see appendix A). ${ }^{14}$ Table 2 provides summary statistics for the firm-specific variables used in this study, averaged within industries and over time.

\subsection{Estimation of the cash flow response parameters}

In appendix $\mathrm{C}$, the procedure used to estimate the firm-specific cash flow response parameters is derived from eqs. (4) and (6). The procedure employed with quarterly data is described by eq. (11) below. Recall that eq. (4) would

\footnotetext{
${ }^{13}$ Unless measurement errors are perfectly correlated over time, the use of annual data must diversify some of the measurement error in quarterly data. Aside from this, there are other reasons to suspect that measurement error is more serious in quarterly than in annual data. Error is more likely to be serious in quarterly measures of unexpected inflation, in part, because the three-week lag with which the Consumer Price Index is reported is lengthy relative to a quarterly period. Quarterly accounting data are also more likely to contain measurement error. Quarterly accounting reports are unaudited, and rely more heavily on approximations than do annual reports. Moreover, the techniques used here to adjust quarterly operating income for inflation involve extrapolations not required in the case of annual data. Specifically, the annual inflation adjustment for cost-of-sales is allocated to quarters in proportion to the real levels of quarterly sales. Also, for those firms not reporting depreciation and interest on a quarterly basis, quarterly income before depreciation and interest was estimated by assuming those two expenses were incurred evenly throughout the year.

${ }^{14}$ Supplemental tests indicated that the use of measurement techniques more refined than those of French et al. had an important effect on the final estimates only when financial institutions were included in the sample. French et al. excluded financial institutions in their study.
} 


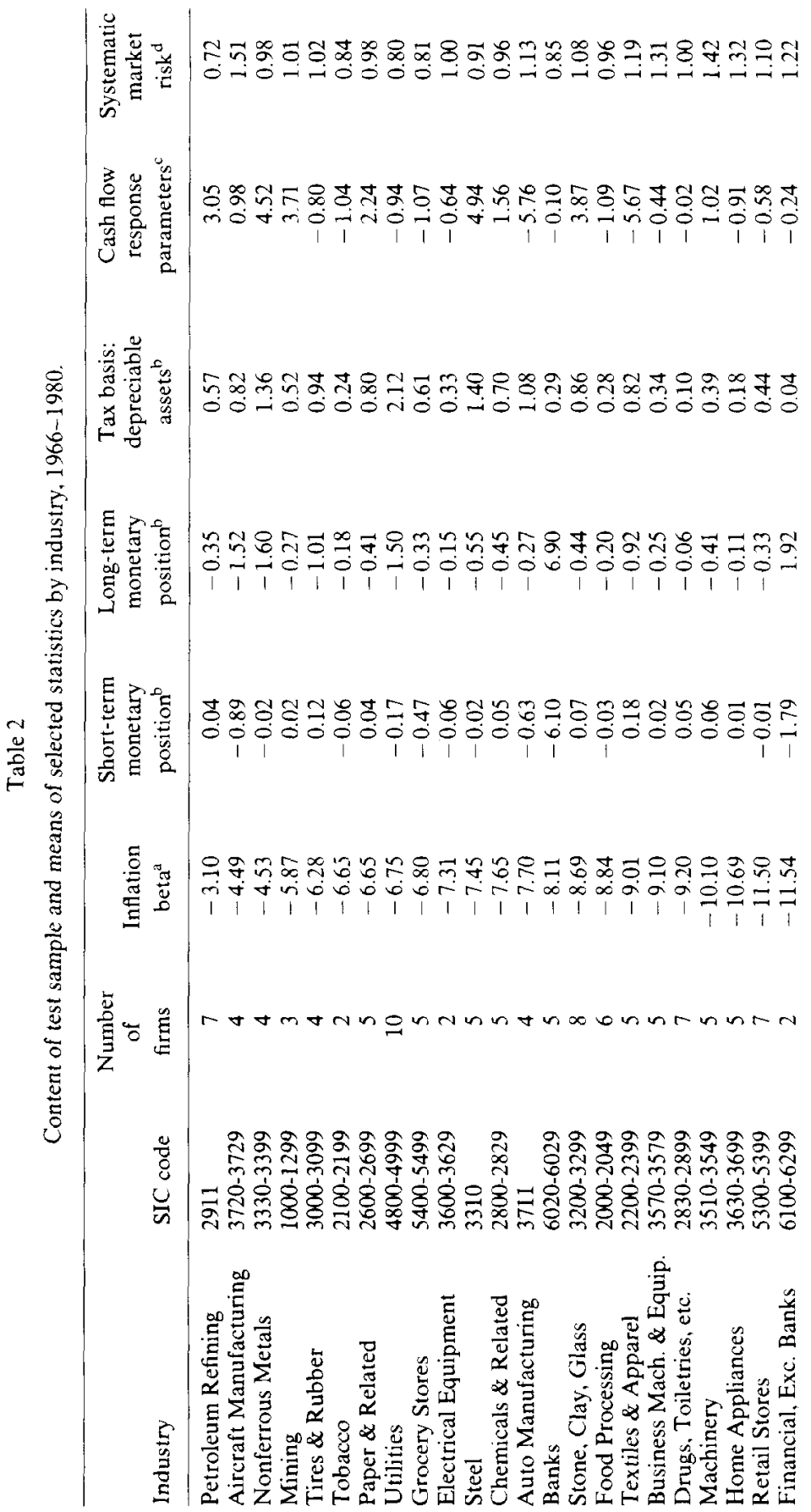




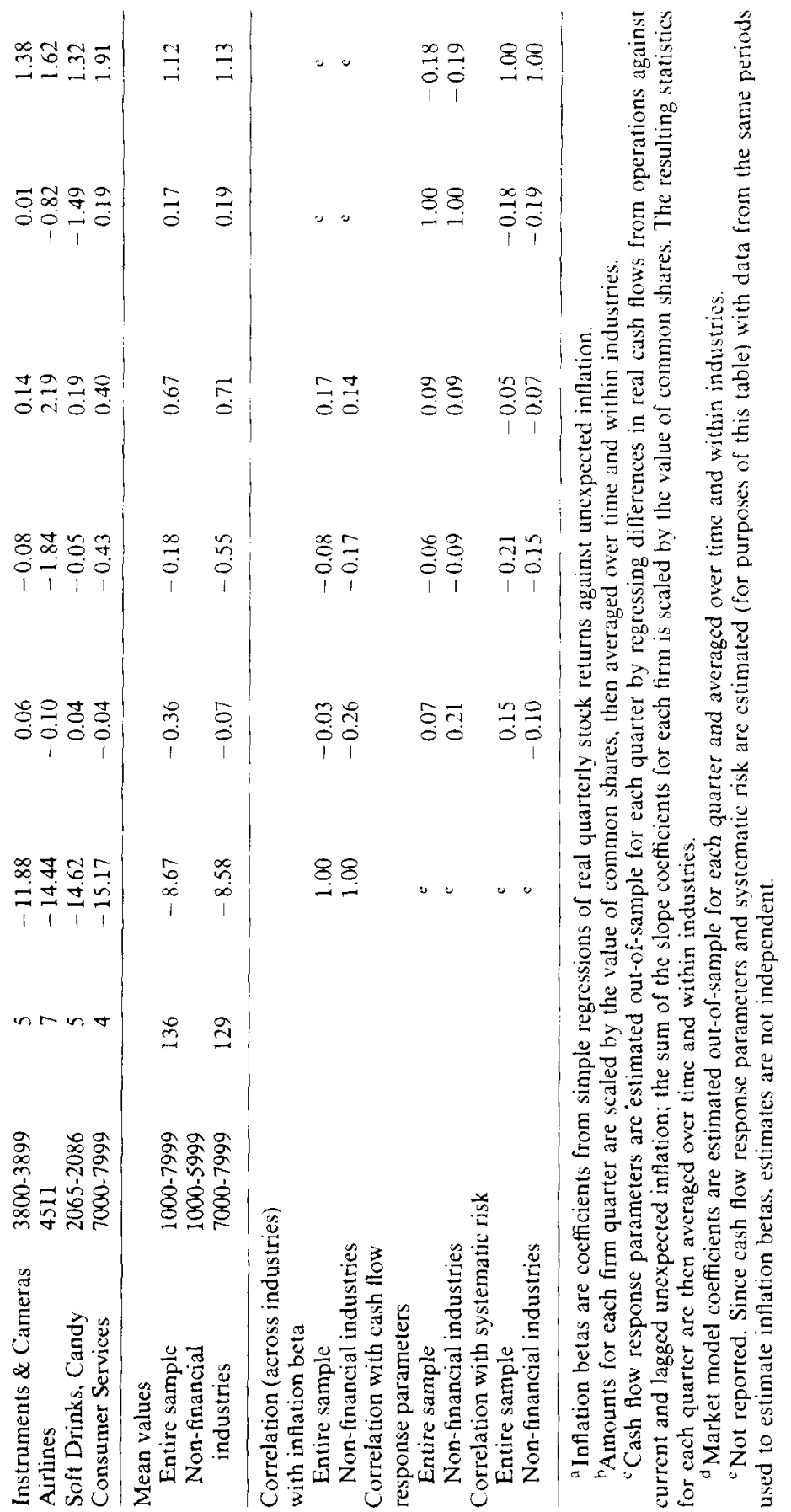


imply that the expected real cash flows for quarter $t$, as of the end of quarter $t-4$, are equal to realized cash flows for quarter $t-4$, plus a constant drift term. Then the dependent variable in eq. (11) can be viewed as an estimate of the change in expected real cash flows from operations, from period $t-4$ through period $t$, plus drift. That change in expected cash flows is expressed as a function of unexpected inflation of periods $t-3$ through period $t$. Finally, note that in eq. (11), measures of common shares outstanding $\left(S_{j t}\right)$ are introduced in such a way as to control the impact on the dependent variable of growth through issue of additional stock,

$$
\left[\frac{\tilde{C}_{j t}}{\tilde{S}_{j t}}-\frac{\tilde{C}_{j, t-4}}{\tilde{S}_{j, t-4}}\right] \tilde{S}_{j, t-4}=d_{j}+\theta_{j 1} \tilde{u}_{t}+\cdots+\theta_{j 4} \tilde{u}_{t-3}+\tilde{\varepsilon}_{j t},
$$

where

$\tilde{C}_{j t}=$ real (inflation-adjusted) cash flows from operations for firm $j$ in period $t$

$\tilde{S}_{j t}=$ number of common shares outstanding (adjusted for splits and stock dividends) for firm $j$ in period $t$,

$\tilde{u}_{t}=$ unexpected inflation for period $t$,

$\theta_{j n}=$ cash flow response parameters for firm $j$, lag $n$,

$d_{i}=$ intercept, representing constant drift in cash flows,

$\tilde{\varepsilon}_{j t}=$ a random shock with mean zero.

If data from the same periods were used to estimate both eq. (11) and eq. (10), then the estimate of $k_{5}$ in eq. (10) would be upward-biased. To avoid this bias, cash flow response parameters used in eq. (10) for a given period are estimated while excluding up to five observations in and surrounding that period. ${ }^{15}$

\footnotetext{
${ }^{15}$ Consider the use of period $\tau$ data in the estimation of the cash flow response parameters that are, in turn. used to explain period $t$ stock returns. If $\tau-q=t$, where $q=0,1,2$, or 3 , then the dependent variable in eq. (11) (that is, seasonally differenced cash flows of period $t+q$ ) would likely be correlated with the dependent variable in eq. (10) (that is, period $t$ stock returns). Furthermore, one of the independent variables in eq. (11) (that is, unexpected inflation of period $t$ ) would be perfectly correlated with the same independent variable appearing in eq. (10). The positive correlation of the variables appearing in the two equations would tend to make the estimate of $k_{s}$ in eq. (10) positive, even if the cash flow response parameters truly had no explanatory power. To avoid that bias, the cash flow response parameters must he estimated while excluding observations where fiscal quarter $\tau-q(q=0,1,2,3)$ overlaps with or is equivalent to calendar quarter $t$. That approach requires exclusion of four observations for firms with fiscal years ending in March, June, September, and December, and five observations for other firms.

When $\tau-q \neq i$ for all $q$, no bias should result so long as either (i) unexpected inflation is serially uncorrelated and contemporaneously impounded in stock returns, or (ii) stock returns of period $t$ are not correlated with seasonally differenced cash flows of period $\tau-q$. Supplemental tests confirmed that when additional observations surrounding the four-to-five quarter window described above are eliminated, the final results are nearly identical to (and actually slightly stronger than) the primary results reported here.
} 
Table 3

Results of tests of hypothesis that cash flow response parameters are equal across all firms or industries. ${ }^{a}$ Data are quarterly observations from 1966:I to 1980:IV.

\begin{tabular}{|c|c|c|c|c|c|}
\hline Test & $\begin{array}{c}\text { Cross-sectional } \\
\text { units }\end{array}$ & $\begin{array}{c}\text { Assumptions } \\
\text { on } \\
\text { covariance } \\
\text { matrixh }^{h}\end{array}$ & $F$-statistic & $\begin{array}{l}\text { Degrees } \\
\text { of } \\
\text { freedom }\end{array}$ & $\begin{array}{c}\text { Significance } \\
\text { level }\end{array}$ \\
\hline (1) & 136 firms & Diagonal & 4.24 & 135.7344 & 0.0001 \\
\hline (2) & 27 industries & Diagonal & 5.29 & 26,1458 & 0.0001 \\
\hline (3) & 27 industries & Full & 7.84 & 26,1458 & 0.0001 \\
\hline
\end{tabular}

"Null hypothesis is that $\sum_{n=1}^{4} \theta_{j n} / V_{, 80: \mathrm{IV}}$ is the same for all firms/industries $j$, where $V_{j, 80: \mathrm{IV}}$ is the value of common shares at the beginning of the fourth quarter of 1980 , and the cash flow response parameters $\theta_{1 n}$ are estimated as follows, using quarterly data from 1966 through the third quarter of 1980 :

where

$$
\left[\tilde{C}_{t} / \tilde{S}_{t}-\tilde{C}_{t-4} / \tilde{S}_{t-4}\right] \tilde{S}_{t}=d_{0}+\theta_{1} \tilde{u}_{t}+\cdots+\theta_{4} \tilde{u}_{t-3}+\tilde{\varepsilon}_{t} .
$$

$\tilde{C}_{t}=$ real cash flows from operations for quarter $t$, in base-period dollars,

$\tilde{S}_{t}=$ common shares outstanding for quarter $t$, adjusted for stock dividends and splits.

$\tilde{u}_{t}=$ unexpected inflation for quarter $t$.

$\tilde{F}_{1}=$ randomly distributed disturbance with mean zero.

"The covariance matrix is defined as the $J \times J$ matrix of contemporaneous covariances:

$$
\sigma_{t \prime}=\operatorname{cov}\left[\varepsilon_{t r}, \varepsilon_{l t}\right] \text { for } i=1,2, \ldots, J \text { and } j=1,2, \ldots, J \text {, }
$$

where $i$ and $j$ are firm/industry subscripts.

Two conditions must hold if the cash flow response parameters are to explain the differential reaction of firms' stock returns to unexpected inflation. First, the cash flow response parameters must themselves differ across firms. Second, given that they are estimated out-of-sample, there must exist at least some stationarity in the cross-sectional rankings of the parameters. Before turning to the primary empirical tests, the existence of these two conditions is examined.

Table 3 presents tests of the significance of cross-sectional differences in the cash flow response parameters. The tests are analogous to those used in section 2 to examine cross-sectional differences in the reaction of stock returns to unexpected inflation. In each case, the null hypothesis is that the term $\sum_{n=1}^{4} \theta_{j n t} / V_{j, t-1}$ in eq. (10) is the same across all firms or industries. Although in the primary empirical tests that term is re-estimated for each quarter from 1966 through 1980, the results in table 3 are based only on the cash flow response parameters estimated for the last quarter of 1980. (Other estimation periods are overlapping and non-independent, and thus yield similar results.) All of the test statistics presented in table 3 permit rejection, at the 0.05 level, of the hypothesis that the sum of the current and lagged response of real cash flows from operations to unexpected inflation is the same across firms or industries. 
To assess whether a reasonable degree of stationarity exists in the cross-sectional rankings of the cash flow response parameters, cross-sectional correlations are calculated between the response parameters estimated in the three consecutive five-year subperiods from 1966 through $1980 .{ }^{16,17}$ The correlation between the parameters estimated in the 1976-1980 subperiod, and corresponding estimates from the 1971-1975 subperiod is positive (0.41) and sufficiently high to permit rejection of the hypothesis of zero or negative correlation at the 0.0001 level of significance. The correlation between estimates from 1976-1980 and 1966-1970 is much smaller (0.13), but allows rejection of the hypothesis of zero or negative correlation at the 0.07 level. Finally, estimates from 1966-1970 and 1971-1975 have a correlation that is close to zero $(0.06)$. Thus, the results are indicative of some stationarity in the cross-sectional rankings of the inflation response parameters, except in the comparison of the two earliest subperiods. The primary empirical tests of the following section will serve, in part, as potentially more powerful, if less direct, tests of intertemporal stationarity in the cross-sectional rankings of the response parameters. ${ }^{18}$

\footnotetext{
${ }^{16}$ For purposes of this test, the cash flow response parameters are estimated in a manner similar to that used in the primary empirical tests for the quarters 1970:IV, 1975:IV, and 1980:IV. The only difference is that here, response parameters for a given quarter are estimated using only data from the five prior years.

${ }^{17}$ The stationarity of the cash flow response parameters was also assessed using an alternative approach. A standard $F$-test [Madalla (1977, pp. 194-201)] was used to test the hypothesis that, for a given firm, the coefficients $\theta_{j 1}$ through $\theta_{j 4}$ in eq. (11) are equal across the three consecutive five-year subperiods from 1966 through 1980 . One can reject the hypothesis of stationarity at the 0.05 level for 20 of the 136 firms in the sample. Of course, failure to reject the hypothesis of stationarity for the remaining 116 firms does not necessarily indicate that stationarity exists in those cases.

${ }^{1 *}$ Although the underlying causes of the differences among the cash flow response parameters are not identified here, certain characteristics of the estimated parameters reported in table 2 are particularly striking. The six industries with the highest estimated response parameters (steel. non-ferrous metals, stonc/clay/glass, mining, petroleum, pulp/paper) are all involved in the extraction and/or processing of metals and minerals, or processing of timber. Thus, the data are consistent with the conventional wisdom that natural resources are a good hedge against inflation. The two industries with extreme negative estimated cash flow response parameters (auto manufactusers and textiles/apparel) both produce some goods for which demand is relatively elastic in the short run. Such negative response parameters could result from an income effect of inflation upon consumer demand. That is, if unexpected inflation, through impacts on income taxes or the real value of monetary claims, redistributes wealth from the wealthier consumers to the government and ultimately to less wealthy consumers, relative demand for specific consumer goods would shift according to the income elasticity of demand for those goods. Such an income effect could also be explained by the negative association between unexpected inflation and real aggregate activity.

An alternative explanation for the differences among the response parameters is based on a hypothesis advanced by Okun (1981), under which nominal price flexibility is constrained in certain 'customer markets', but not in 'auction markets'. The two industries with the most negative response parameters would be classified in 'customer markets', and most of the industries with the highest response parameters would be classified in 'auction markets'. [See Okun (1981, esp. pp. (66-167).]
} 


\section{Primary empirical tests}

\subsection{Methodology}

The primary empirical tests involve estimating the magnitudes of the effects that, according to the model of section 2, should explain cross-sectional differences in the associations of stock returns with unexpected inflation. Eqs. (3) and (10) of section 2 are estimated here, using seemingly unrelated regression (SUR) [see Judge, Griffiths, IIill and Lee (1980, sec. 6.1)]. This approach to estimation is adopted because the disturbance terms $\tilde{e}_{j}$ are likely to be cross-sectionally correlated. The SUR approach directly estimates crosssectional correlation in the terms $\tilde{e}_{j t}$ and takes such correlations into account when generating estimated coefficients. To permit estimation of the cross-sectional correlations, however, the number of cross-sectional units must be less than the number of available time series observations. Since only 60 quarterly time series observations are available here, it is required that the 136 sample firms be grouped into a lesser number of portfolios.

Two alternative methods of grouping firms into portfolios are employed here. The first approach, employed by French, Ruback and Schwert (1983), is to form 'sequentially updated portfolios' based on rankings of the independent variables of the 136 sample firms. The second approach is to group firms into the same 27 industry portfolios that were described in table 2. As will be discussed, there are indications that the approach based on industry portfolios may be more powerful. However, results based on both approaches are reported, since there are some important differences, and because results based on the sequentially updated portfolios will permit a more direct comparison with the results of French, Ruback and Schwert (1983).

The estimated regressions are presented in table 4 . The estimates based on sequentially updated portfolios are labeled $S E Q(A), S E Q(B)$, and $S E Q(C)$; those based on industry portfolios are labeled $I N D(A), I N D(B)$, and $I N D(C)$. Models $\operatorname{SEQ}(A)$ and $I N D(A)$ are estimates of eq. (3). These models exclude the cash flow response parameters and systematic risk, and should facilitate comparison with prior research. Models $\operatorname{SEQ}(B)$ and $\operatorname{IND}(B)$ are also estimates of eq. (3), but in these models, estimates of $k_{1,}$ are constrained to be equal across portfolios (see section 2.2.4). Models $S E Q(C)$ and $I N D(C)$ are estimates of eq. (10), and thus, include all the independent variables that were introduced in section 2 .

\subsection{Results: Sequentially updated portfolios}

The purpose of the sequentially updated portfolio technique is to group firms into portfolios while preserving a large cross-portfolio variance in the independent variables. To estimate models $S E Q(A)$ and $S E Q(B)$, the 136 
Table 4

Estimates of magnitudes of sources of differences in associations of stock returns with unexpected inflation, based on seemingly unrelated regression with quarterly data, 1966-1980. Gencral form of regression equation is: ${ }^{2}$

\begin{tabular}{|c|c|c|c|c|c|c|}
\hline \multicolumn{7}{|c|}{$\tilde{R}_{n}=b_{1,}+k_{1,} \tilde{u}_{t}+k_{2} \frac{S T M P_{j, t-1}}{V_{j, t-1}} \tilde{u}_{t}+k_{3} \frac{L T M P_{j, 1-1}}{V_{j, t-1}} \tilde{u}_{t}+k_{4} \frac{T A X_{j, 1-1}}{V_{j, t-1}} \tilde{u}_{t}+k_{5} \frac{\sum_{n} \theta_{, m}}{V_{j, t-1}}$} \\
\hline & \multicolumn{6}{|c|}{ Estimated coefficients (t-statistics in parentheses) } \\
\hline & $\hat{k}_{1}$ & $\hat{k}_{2}$ & $\hat{k}_{3}$ & $\hat{k}_{4}$ & $\hat{k}$ & $\hat{k}_{b}$ \\
\hline \multicolumn{7}{|c|}{136 firms grouped into sequentially updated portfolios } \\
\hline$S E Q(A)$ & $\begin{array}{l}\text { varies over } \\
27 \text { portfolios }\end{array}$ & $\begin{array}{l}1.13 \\
(1.62)\end{array}$ & $\begin{array}{c}0.89 \\
(1.41)\end{array}$ & $\begin{array}{c}0.93 \\
(0.79)\end{array}$ & - & -- \\
\hline$S E Q(B)$ & $\begin{array}{l}-6.56^{\mathrm{h}} \\
(-4.83)\end{array}$ & $\begin{array}{c}0.42 \\
(0.81)\end{array}$ & $\begin{array}{c}0.52 \\
(1.13)\end{array}$ & $\begin{array}{c}1.27 \\
(2.00)\end{array}$ & - & - \\
\hline$S E Q(C)$ & $\begin{array}{r}-5.68^{c} \\
(-3.76)\end{array}$ & $\begin{array}{c}-1.22 \\
(-3.25)\end{array}$ & $\begin{array}{c}-0.50 \\
(-1.53)\end{array}$ & $\begin{array}{c}0.34 \\
(0.74)\end{array}$ & $\begin{array}{c}0.20 \\
(4.03)\end{array}$ & $\begin{array}{c}-3.33 \\
(-3.59)\end{array}$ \\
\hline \multicolumn{7}{|c|}{136 firms grouped into industry portfolios } \\
\hline$I N D(A)$ & $\begin{array}{l}\text { varies over } \\
27 \text { industries }\end{array}$ & $\begin{array}{c}-1.52 \\
(-2.01)\end{array}$ & $\begin{array}{c}-2.04 \\
(-3.15)\end{array}$ & $\begin{array}{c}0.34 \\
(0.32)\end{array}$ & - & 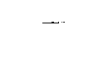 \\
\hline$I N D(B)$ & $\begin{array}{l}-3.51^{\mathrm{d}} \\
(-2.57)\end{array}$ & $\begin{array}{c}-2.54 \\
(-5.10)\end{array}$ & $\begin{array}{c}-2.19 \\
(-5.20)\end{array}$ & $\begin{array}{l}-1.51 \\
(-2.75)\end{array}$ & $\ldots$ & - \\
\hline$I N D(C)$ & $\begin{array}{r}-0.44^{\mathrm{e}} \\
(-0.28)\end{array}$ & $\begin{array}{c}-2.41 \\
(-4.62)\end{array}$ & $\begin{array}{c}-2.14 \\
(-4.95)\end{array}$ & $\begin{array}{c}-1.62 \\
(-2.91)\end{array}$ & $\begin{array}{c}0.11 \\
(1.23)\end{array}$ & $\begin{array}{c}-7.09 \\
(-3.86)\end{array}$ \\
\hline
\end{tabular}

${ }^{a} R=$ real stock return for portfolio $j$, quarter $t ; u=$ unexpected inflation: $S T M P=$ short-term monetary position: $L T M P=$ long-term monetary position: $T A X=$ tax basis of depreciable assets: $\sum \theta=$ cash flow response parameters; $\beta=$ systematic risk: $V=$ value of common shares. Estimates of $\sum \theta$ and $\beta$ for period $t$ are always based on data independent of period $t$.

' The hypothesis that $k_{1 ;}$ is the same for all $j$ can be rejected at the 0.0002 level, based on $F(26.1563)=2.32$.

"The hypothesis that $k_{1}$, is the same for all $j$ can be rejected at the 0.0002 level, based on $F(31,1851)=2.18$.

"The hypothesis that $k_{1}$, is the same for all $j$ can be rejected at the 0.02 level, based on $F(26,1563)=1.63$.

"The hypothesis that $k_{1 j}$ is the same for all $j$ can be rejected at the 0.23 level, based on $F(26,1561)=1.19$.

sample firms are first ranked on the basis of values for $L T M P$ (scaled by the value of common shares) for a given quarter. The 45 firms with the highest scaled values for $L T M P$ are placed in one group; the 45 firms with the next highest values are placed in another group; the remaining 46 firms are placed in a third group. Each of these groups is then further divided into three subgroups of 15 or 16 firms, based on rankings of TAX (also scaled by the value of common shares) within the three original groups. Finally, a third 
division is made, based on rankings of scaled values of $S T M P{ }^{19}$ In the end, 27 portfolios of 5 or 6 firms remain. This procedure is repeated for each of the 60 quarters in the estimation period, yielding time-series data for each of the 27 sequentially updated portfolios. The portfolio grouping procedures are modified slightly for $S E Q(C)$, because that model includes more independent variables. Firms are segregated into two groups, first on the basis of rankings of scaled values of $\sum \theta$, then, successively, on the basis of rankings of $\beta$, and scaled values of $L T M P, T A X$, and STMP. ${ }^{20}$ This procedure yields 32 portfolios of 4 or 5 firms each.

SUR estimates of models $S E Q(A), S E Q(B)$, and $S E Q(C)$ appear in the first panel of table 4 . The predicted signs of the estimated coefficients are as follows. Under the nominal contracting hypothesis, the estimated coefficients of $S T M P, L T M P$, and $T A X$ (that is, $\hat{k}_{2}, \hat{k}_{3}$, and $\hat{k}_{4}$ ) should be negative. If unexpected inflation affects operating cash flows in a way that differs predictably across firms, then the estimated coefficient of $\sum \theta$ (that is, $\hat{k}_{5}$ ) should be positive. If negative associations between stock returns and unexpected inflation reflect positive associations between stock returns and aggregate real activity, the estimated coefficient of $\beta$ (that is, $\hat{k}_{6}$ ) should be negative.

Like models used in previous research, models $S E Q(A)$ and $S E Q(B)$ include only measures of firms' net short-term and long-term monetary positions, and tax shields. Although the nominal contracting hypothesis predicts that $k_{2}, k_{3}$, and $k_{4}$ should all be negative, estimates of those coefficients are always positive in both $S E Q(A)$ and $S E Q(B)$. Thus, these estimates provide no support for the nominal contracting hypothesis.

$S E Q(C)$ includes all of the independent variables. Estimated coefficients of the newly introduced variables, $\sum \theta$ and $\beta$, both assume the predicted signs and are statistically significant at the 0.0001 level. Furthermore, the estimated coefficients $\hat{k}_{2}$ and $\hat{k}_{3}$ are negative, as predicted by the nominal contracting hypothesis. The estimate $\hat{k}_{2}$ is significant at the 0.0006 level, and $\hat{k}_{3}$ is significant at the 0.063 level. Since $\hat{k}_{4}$ is nominally positive, the results are still not totally consistent with the nominal contracting hypothesis. However, inclusion of the two additional factors in the model does dramatically increase the degree of support for the importance of nominal contracting effects. Supplemental tests revealed that the cash flow response parameters and

\footnotetext{
${ }^{1 '}$ The procedure is intended to result in the maximum possible variation in $L T M P$, and less variation in $T A X$ and STMP. The order of the ranking is the same as that used by French, Ruback and Schwert (1983). They choose that order of ranking because the reaction of stock prices to changes in expected inflation should be larger for nominal contracts of longer duration I.TMP is expected to have a longer average duration than $T A X$, which has a longer duration than $S T M P$.

${ }^{20}$ Firms were ranked first on the basis of the cash flow response parameters and systematic risk, in order to maximize variation in those factors and thus maximize the potential to control any possible misspecification bias in the model that excluded those factors.
} 
systematic risk must both be included to obtain any support whatsoever for the nominal contracting hypothesis, when sequentially updated portfolios are used. That is, when either factor is excluded, each of the estimates $\hat{k}_{2}, \hat{k}_{3}$, and $\hat{k}_{4}$ remain positive. This is not unexpected; an examination of correlations among the independent variables indicates that exclusion of systematic risk or the cash flow response parameters could create upward bias in $\hat{k}_{2}, \hat{k}_{3}$, and $\hat{k}_{4} \cdot{ }^{21}$

The significantly positive estimate of $k_{5}$ suggests that the underlying firm characteristics represented by the cash flow response parameters explain a portion of the cross-sectional differences in the associations of stock returns with unexpected inflation. Given that the cash flow response parameters are estimated out-of-sample, the result is consistent with some stationarity in the cross-sectional rankings of these response parameters. ${ }^{22}$ The significantly negative estimate of $k_{6}$ is consistent with the hypothesis that part of the cross-sectional differences in associations of stock returns with unexpected inflation simply reflects the differential impact of changes in aggregate real activity, which itself is negatively correlated with unexpected inflation.

Finally, although models $S E Q(B)$ and $S E Q(C)$ constrain the estimate $\hat{k}_{1}$ to be equal for all $j$, the hypothesis that $k_{1 j}$ is constant across $j$ can be rejected at the 0.002 level. However, comparison of results for $\operatorname{SEQ}(B)$, which imposes the constraint, with $\operatorname{SEQ}(A)$, which does not, indicates that the constraint has little impact on the common parameter estimates.

\subsection{Results: Industry portfolios}

SUR estimates of models $I N D(A), I N D(B)$, and $I N D(C)$ appear in the second panel of table 4 . The results differ from those discussed above as

\footnotetext{
${ }^{21}$ Some indication of the likely effects of the omission of variables can be obtained through specification analysis [Theil (1971, sec. 11.2)]. The partial correlation of the cash flow response parameters with STMP, LTMP, and TAX is positive in each case, so STMP, LTMP, and TAX could tend to proxy for the response parameters that are omitted in $S E Q(B)$; since $k_{5}$ (the coefficient of the cash flow response parameters) is expected to be positive, this would induce upward bias in the estimated coefficients of $S T M P, L T M P$, and $T A X$. The partial correlation of systematic risk with $S T M P, L T M P$, and $T A X$ is negative in each case, so $S T M P, L T M P$, and $T A X$ could serve as negative proxies for systematic risk, which is omitted in $S E Q(B)$; since $k_{6}$ (the coefficient of systematic risk) is expected to be negative, this would also induce upward bias in the estimated coefficients of STMP, LTMP, and TAX.

Even though it appears likely that omission of either the response parameters or systematic risk would tend to bias the coefficients so as to reduce support for the nominal contracting hypothesis, the actual effect of the omission also depends on characteristics of the residual covariance matrix, unidentified omitted variables, and other factors.

${ }^{22}$ Recall that the cash flow response parameters are estimated using data from periods both prior to and subsequent to the period for which stock price behavior is explained. Bernard (1984) shows that it is also possible to predict stock price reaction to unexpected inflation on the basis of cash flow response parameters estimated solely with prior period data.
} 
follows. First, support for the nominal contracting hypothesis is much stronger. Second, the explanatory power of the cash flow parameters in model $I N D(C)$ is not significant, whereas it was highly significant in model $S E Q(C)$.

Models $I N D(A)$ and $I N D(B)$ include only those independent variables present in prior research. Model $I N D(A)$ provides some support for the nominal contracting hypothesis in that both $\hat{k}_{2}$ and $\hat{k}_{3}$ are significantly negative. However, $\hat{k}_{4}$ is nominally positive, contrary to the implications of the nominal contracting hypothesis.

Model $I N D(B)$ is the same as $I N D(A)$, except that $\hat{k}_{1 j}$ is constrained to be equal across industries. Although imposition of that constraint did not have much impact on the estimates when sequentially updated portfolios were used, that constraint has an important effect for industry portfolios. In model $I N D(B)$, the coefficient $\hat{k}_{4}$, in addition to $\hat{k}_{2}$ and $\hat{k}_{3}$, is significantly negative, as predicted by the nominal contracting hypothesis. However, since the hypothesis that $k_{1 j}$ is the same for all portfolios can be rejected at the 0.02 level, it is possible that imposition of the constraint on $\hat{k}_{1 j}$ creates bias due to misspecification. ${ }^{23}$

Model $I N D(C)$ includes all the independent variables in eq. (10). All the estimated coefficients in $I N D(C)$ have signs that are consistent with predictions, and, with the exception of $\hat{k}_{5}$, all are significant beyond the 0.01 level. Therefore, model $I N D(C)$ provides strong support for the nominal contracting hypothesis. It also indicates that a significant portion of the differential effects of unexpected inflation are explained by variation in systematic risk. Finally, in $I N D(C)$, it is not possible to reject the hypothesis that the parameters $k_{1 j}$ are equal across portfolios, at any conventional significance level. Thus, there is less concern about potential misspecification bias due to the constraint on $\hat{k}_{1}$. In addition, this indicates that in the full model $[\operatorname{IND}(C)]$, if there remain any omitted effects of unexpected inflation that vary cross-sectionally (and which could thus be captured by the terms $\hat{k}_{1 j} \tilde{u}_{t}$ ), those omitted effects are not significant.

That the support for the nominal contracting hypothesis is stronger when industry portfolios are used, rather than sequentially updated portfolios, may

\footnotetext{
${ }^{23}$ The constraint that $\hat{k}_{1 j}$ be equal across industries can create bias if $k_{1}$ is correlated with the remaining independent variables. Since the constraint on $\hat{k}_{1}$, has the greatest impact on the estimate of $k_{4}$ (the coefficient of $T A X$ ), that impact was investigated further. The correlation between the estimated values of $k_{1}$, and $T A X$ is negative, but only because of the airlines' extreme ncgative value for $\hat{k}_{1 j}$ and extreme positive value of $T A X$. This suggests that $\hat{k}_{4}$ in $I N D(B)$ could be downward-biased because it reflects a negative impact of unexpected inflation on airlines that is omitted in model $I N D(R)$, but captured by $\hat{k}_{1}$ in model $I N D(A)$. When the airlines were excluded from the sample, the estimate of $k_{4}$ in $I N D(B)$ remained negative, but was significant only at the 0.23 level. However, the full model $[I N D(C)]$ is less sensitive to the exclusion of airlines from the sample: $\hat{k}_{4}$ is significantly negative at the 0.10 level (and other estimates are essentially unchanged) when airlines are excluded.
} 
be due to differences in the power of the two techniques for testing that hypothesis. There are two reasons to suspect that industry portfolios would provide a more powerful test. The first is that, even though the sequentially updated portfolio technique is designed to maximize the variation in the independent variables, the variation in both STMP and LTMP is actually much higher when firms are grouped by industry. ${ }^{24}$ This occurs because industry groupings always yield two portfolios consisting only of financial institutions, which have extreme values for STMP and LTMP (see table 2). In contrast, the sequentially updated portfolio technique must always combine at least some of the financial institutions in portfolios with non-financial firms, thus 'diversifying' the extreme values for STMP and LTMP.

The second (and probably more important) reason that the industry portfolios may provide more powerful tests is that residual cross-sectional correlation is less troublesome under the industry portfolio approach. When sequentially updated portfolios are used, not only is the degree of residual cross-sectional correlation higher, ${ }^{25}$ but, more importantly, the assumption that the residual covariance matrix is stationary is almost certainly violated, since the contents of the sequentially updated portfolios change from period to period. When the sequentially updated portfolio technique is modified so as to reduce non-stationarity in the residual covariance matrix, the results are much more comparable to those based on industry portfolios. The modification involves forming portfolios in each quarter, based on the firms' average values of the independent variables over all quarters, rather than the values for the given quarter. Under the modified approach, firms are classified in the same portfolio in every quarter. So long as the residual correlation between firms remains stationary, the residual correlation among these portfolios should be stationary. Even though under this modified approach variation in the independent variables is reduced in all cases, this approach yields results that are

\footnotetext{
${ }^{24}$ The sequentially updated portfolio technique is intended to yield more variation in the independent variables that are used first in the ranking process. Since LTMP and STMP were used third and fifth, respectively, in the series of rankings, it is possible that the order of the ranking accounts for the low variation in those variables. To check this possibility, sequentially updated portfolios were formed again, ranking first on $L T M P$, then on TAX,STMP, the cash flow response parameters, and systematic risk. This procedure yielded portfolios that had less variation in all independent variables except $T A X$. Variation in $L T M P$ and STMP changed little because that variation depends greatly on the degree to which financial institutions are groupcd in portfolios with non-financial firms, and the portfolio assignments of the financial institutions are largely insensitive to the order of the ranking.

${ }^{25}$ Residual correlation is higher because the sequentially updated portfolios are better diversified than industry portfolios. Average residual cross-sectional correlation is estimated to be 0.64 in model $S E Q(C)$ and 0.53 in model $I N D(C)$.
} 
more consistent with the nominal contracting hypothesis than when sequentially updated portfolios are used. ${ }^{26,27}$

\subsection{Results: Comparison with prior research}

Since the results pertaining to the nominal contracting hypothesis differ from those in prior research, it is important to isolate reasons for the differences. The results are compared here with those of French, Ruback and Schwert (1983), whose methods are most like those used in this paper.

The chart below summarizes the degree of support for the nominal contracting hypothesis, under alternative specifications. In addition to summarizing the effect of (i) expanding the model from eq. (3) to eq. (10), and (ii) alternative portfolio formation techniques, the chart also summarizes the effect of including financial institutions in the sample. The tests are repeated using only non-financial firms, both to make the sample more comparable to that used by French, Ruback and Schwert and because financial firms may have an important impact on the power to identify nominal contracting effects. It is apparent in table 2 that banks and other financial institutions have extreme values for both STMP and LTMP. They therefore account for much of the variation in those independent variables. Indeed, in a study that examined only financial institutions, Flannery and James (1984) detected security price behavior consistent with the nominal contracting hypothesis.

In table 5, the nominal contracting hypothesis is said to have "strong support' if $\hat{k}_{2}, \hat{k}_{3}$, and $\hat{k}_{4}$ are all significantly less than zero at the 0.05 level, and one cannot reject the hypothesis (at the 0.05 level) that $k_{1}$, is the same across portfolios. 'Some support' means that at least two of the estimates $\hat{k}_{2}$, $\hat{k}_{3}$, or $\hat{k}_{4}$ are significantly less than zero at the 0.10 level.

The results most comparable to those of French, Ruback and Schwert (1983) are located in the upper left-hand cell of the table. They estimate eq. (3), using

\footnotetext{
${ }^{26}$ In most cases, coefficients estimated using the modified approach lie between those based on the sequentially updated portfolios and the industry portfolios. When the modified approach is used in estimating the full model [eq. (10)], coefficients of STMP, LTMP, and TAX are all negative at the $0.005,0.03$, and 0.20 significance levels, respectively. The coefficients of the cash flow response parameters and systematic risk continue to take on the predicted signs. and are significant at the 0.005 and 0.002 levels, respectively.

${ }^{27}$ Additional estimates of eqs. (3) and (10) were generated, using a technique that permits the use of a diagonal covariance matrix. The technique assumes that any residual cross-sectional correlation is due to a common market-wide effect. [For a detailed discussion of the technique, see Judge. Griffiths, Hill and Lee (1980, sec. 8.4.1).] The supplemental tests permit the use of either annual or quarterly data, and thus allow an assessment of sensitivity of the results to the choice of measurement interval. In addition, the supplemental tests can take advantage of firm-specific information, because they do not require that firms be grouped into portfolios.

Regardless of whether quarterly or annual data are used, results based on the supplemental tests are similar to those based on sequentially updated portfolios.
} 
Table 5

Degree of support for nominal contracting hypothesis.

\begin{tabular}{|c|c|c|c|c|}
\hline & \multicolumn{2}{|c|}{ Non-financial firms only } & \multicolumn{2}{|c|}{ Full sample } \\
\hline & $\begin{array}{l}\text { Sequentially } \\
\text { updated } \\
\text { portfolios }\end{array}$ & $\begin{array}{l}\text { Industry } \\
\text { portfolios }\end{array}$ & $\begin{array}{l}\text { Sequentially } \\
\text { updated } \\
\text { portfolios }\end{array}$ & $\begin{array}{l}\text { Industry } \\
\text { portfolios }\end{array}$ \\
\hline $\begin{array}{l}\text { Estimation } \\
\text { of eq (3) }\end{array}$ & $\begin{array}{l}\text { No } \\
\text { support }\end{array}$ & $\begin{array}{l}\text { No } \\
\text { support }^{\mathrm{a}}\end{array}$ & $\begin{array}{l}\text { No } \\
\text { support }\end{array}$ & $\begin{array}{l}\text { Some } \\
\text { support }\end{array}$ \\
\hline $\begin{array}{l}\text { Estimation } \\
\text { of eq. (10) } \\
\text { (full model) }\end{array}$ & $\begin{array}{l}\text { No } \\
\text { support }\end{array}$ & $\begin{array}{l}\text { Strong } \\
\text { support }\end{array}$ & $\begin{array}{l}\text { Some } \\
\text { support }\end{array}$ & $\begin{array}{l}\text { Strong } \\
\text { support }\end{array}$ \\
\hline
\end{tabular}

"Some support exists if $\hat{k}_{1 j}$ is constrained to be equal across industries.

seemingly unrelated regression, with sequentially updated portfolios formed from as many as 1,184 non-financial firms. For the $1964-1979$ period, which is the one most similar to that used here, French, Ruback and Schwert report a significantly negative value for only one of the coefficients $\hat{k}_{2}, \hat{k}_{3}$, and $\hat{k}_{4}$. (The estimate of $k_{2}$, the coefficient of $S T M P$, is significantly negative at the 0.013 level, using a one-tailed test.) When they employ an alternative definition of unexpected inflation for the 1964-1978 period, estimated coefficients are positive in all three cases, and thus are always inconsistent with the nominal contracting hypothesis.

Table 5 indicates that French, Ruback and Schwert's approach can be modified in a number of ways to obtain support for the nominal contracting hypothesis. Expanding the model to include the cash flow response parameters and systematic risk is not always required to obtain some support for the nominal contracting hypothesis; some support can be obtained by adding financial institutions to the sample and using industry portfolios. However, when either the full sample is used, or industry portfolios are employed, expansion of the model from eq. (3) to eq. (10) is sufficient to obtain some support for the nominal contracting hypothesis.

\subsection{Magnitudes of the components of the effects of inflation}

Although table 4 indicates the statistical significance of the effects explained by STMP, LTMP, TAX, the cash flow response parameters, and systematic risk, it does not directly indicate their economic importance. This section assesses their relative importance in explaining both cross-sectional variation in stock returns, and the behavior of aggregate (sample-wide average) stock returns. 
4.5.1. Relative importance of factors explaining cross-sectional variance in stock returns associated with unexpected inflation

The term $u_{t}^{2} \operatorname{var}\left(b_{2 j t}\right)$ represents the amount of cross-sectional variance in stock returns that is associated with a given amount of unexpected inflation. According to eq. (10), that term can be expanded as follows:

$$
\begin{aligned}
u_{t}^{2} \operatorname{var}\left(b_{2, t}\right)=u_{t}^{2} \operatorname{var}[ & k_{2} \frac{S T M P_{j, t-1}}{V_{j, t-1}}+k_{3} \frac{L T M P_{j, t-1}}{V_{j, t-1}} \\
& \left.+k_{4} \frac{T A X_{j, t-1}}{V_{j, t-1}}+k_{5} \frac{\sum_{n} \theta_{j n t}}{V_{j, t-1}}+k_{6} \beta_{j t}\right] .
\end{aligned}
$$

Table 6 presents estimates of the magnitudes of the various components of $\operatorname{var}\left(b_{2 j t}\right)$, by substituting the estimates of $k_{2}$ through $k_{6}$ from the seemingly unrelated regressions, as well as estimates of the cross-sectional variances and covariances in the values of the corresponding independent variables (averaged over time within portfolios).

Although the estimates in table 6 vary according to whether sequentially updated or industry portfolios are used, the rankings of the magnitudes of the components of $\operatorname{var}\left(b_{2 j l}\right)$ are the same, regardless of the portfolio formation technique. The smallest source of cross-sectional variance is always that associated with differences in the cash flow response parameters; it accounts for only 2 percent to 16 percent of the total inflation-related cross-sectional variance. The cross-sectional variance in returns attributable to the revaluation of the nominal contracts STMP, LTMP, and TAX is larger (explaining 20 percent to 30 percent of the total variance), but not as large as the crosssectional variance explained by systematic risk. The latter source of cross-sectional variance in stock returns explains 46 percent of the total inflation-related cross-sectional variance in. stock returns when sequentially updated portfolios are used, and 91 percent when industry portfolios are used. This result suggests that much, if not most of the differential associations of stock returns with unexpected inflation arises because the latter is correlated with changes in aggregate real activity, which in turn affects firms with higher systematic risk more than others.

\subsubsection{Relative importance of factors explaining association of aggregate stock returns with unexpected inflation}

The magnitude, in the aggregate, of the effects associated with STMP, $L T M P, T A X, \sum \theta$, and $\beta$ are summarized in table 7 . The aggregate effects are estimated by calculating aggregate sample averages for each independent 
Table 6

Components of cross-sectional variance in quarterly stock returns associated with unexpected inflation, $1966-19800^{a}$

\begin{tabular}{|c|c|c|}
\hline \multirow[b]{2}{*}{ Component of $\operatorname{var}\left(b_{2, t}\right)$} & \multicolumn{2}{|c|}{$\begin{array}{l}\text { Magnitude, based on seemingly } \\
\text { unrelated regression estimates }\end{array}$} \\
\hline & $\begin{array}{l}\text { Sequentially } \\
\text { updated } \\
\text { portfolios }\end{array}$ & $\begin{array}{l}\text { Industry } \\
\text { portfolios }\end{array}$ \\
\hline 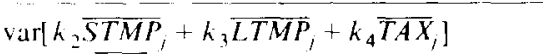 & 0.64 & 0.84 \\
\hline$k \frac{2}{5} \operatorname{var}\left(\sum_{n} \theta_{i n}\right)$ & 0.34 & 0.08 \\
\hline$k_{n}^{2} \operatorname{var}(\bar{\beta})^{\prime \prime \prime}$ & 0.98 & 3.89 \\
\hline Net effect of covariances among above terms & 0.18 & -0.54 \\
\hline Total $\left[\operatorname{var}\left(b_{2,},\right)\right]$ & $\overline{2.14}$ & $4 . \overline{27}$ \\
\hline
\end{tabular}

Analysis is based on decomposition of the cross-sectional variance of the term $b_{2 / r}$, defined by

$$
\tilde{R}_{j t}=b_{1 j}+b_{2, t} \tilde{u}_{t}+\tilde{e}_{j t},
$$

where

$$
h_{2, t}=k_{1}+k_{2} \frac{S T M P_{j t-1}}{V_{j, t}}+k_{3} \frac{L T M P_{j, t-1}}{V_{j, t-1}}+k_{4} \frac{T A X_{j, t-1}}{V_{j, t}}+k_{5} \frac{\sum_{n} \theta_{j n t}}{V_{j, t-1}}+k_{6} \beta_{j t}
$$

and where

$\tilde{R}_{1} \quad=$ stock return for portfolio $j$, quarter $t$,

$\tilde{u}_{t} \quad=$ unexpected inflation, quarter $t$,

$S T M P=$ short-term monetary position,

l.TMP $=$ long-term monetary position,

$T A X=$ tax basis of depreciable assets,

$\sum \theta=$ cash flow response parameters, indicating response of operating profitability to unexpected inflation.

$\beta \quad=$ systematic risk,

$V \quad \Rightarrow$ value of common shares.

hEstimates of $k_{2}$ through $k_{6}$ are from models $S E Q(C)$ and $I N D(C)$ in table 4.

"Overlined variable indicates mean (over time) of variable, scaled (except in the case of $\beta_{\text {) }}$ ) by $V_{1.1}$.

a Portfolios formed from 136 financial and non-financial firms.

variable in eq. (10) (see table 2 ), and then multiplying by the corresponding estimates of $k_{2}$ through $k_{6}$.

The estimates suggest that one percentage point of positive unexpected inflation is associated with an 8 to 9 percent decline in the stock price of the average firm. Compared with that decline, the effects of STMP, LTMP, and $T A X$ are relatively small and, when industry portfolios are used, nearly offsetting in the aggregate. Thus, even though these effects appear important in explaining cross-sectional differences in stock price reaction to unexpected inflation, they appear relatively unimportant in the aggregate. One implication is that, contrary to the assertions of Feldstein and Summers (1979), revaluation of depreciation tax shields does not appear to account for much of the large 
Table 7

Components of association between aggregate (sample average) quarterly stock returns and unexpected inflation, $1966-1980 .^{\mathrm{a}}$

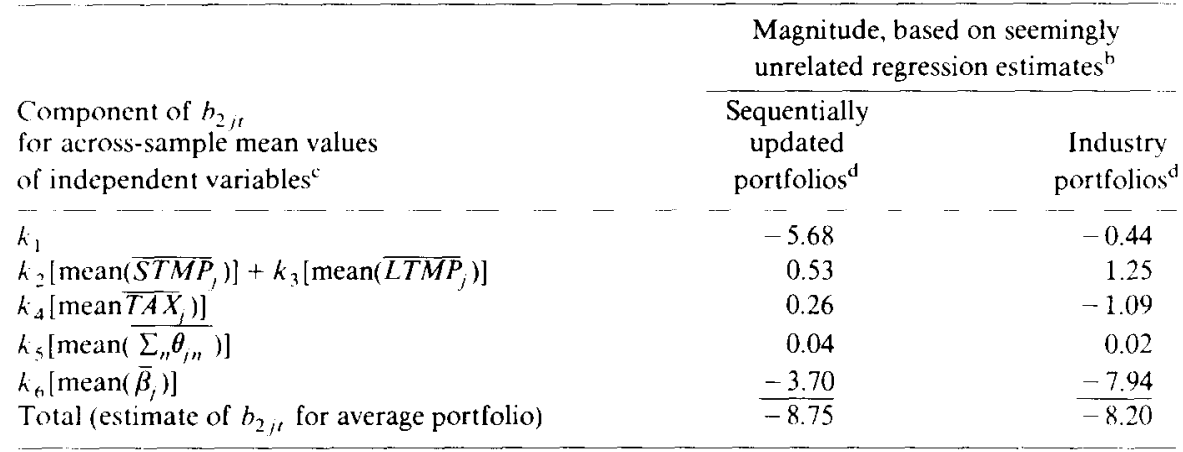

"Analysis is based on decomposition of the term $b_{2 j t}$, defined by

$$
\tilde{R}_{j t}=b_{1 j}+b_{2, t} \tilde{u}_{t}+\tilde{e}_{j r},
$$

where

$$
b_{2, l}=k_{1}+k_{2} \frac{S T M P_{j t-1}}{V_{j, t-1}}+k_{3} \frac{L T M P_{j, t-1}}{V_{j, t-1}}+k_{4} \frac{T A X_{j, t-1}}{V_{j, t-1}}+k_{5} \frac{\sum_{n, n} \theta_{j n t}}{V_{j, t-1}}+k_{6} \beta_{j t},
$$

and where

$\tilde{R}_{k r} \quad=$ stock return for portfolio $j$, quarter $t$,

$\tilde{u}_{,} \quad=$ unexpected inflation, quarter $t$,

$S T M P=$ short-term monetary position,

$L T M P=$ long-term monetary position,

$T A X=$ tax basis of depreciable assets,

$\sum \theta=$ cash flow response parameters, indicating response of operating profitability to uncxpected inflation,

$\beta \quad=$ systematic risk,

$V \quad=$ value of common shares.

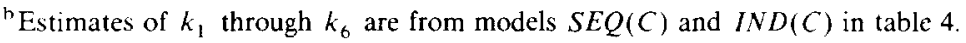

'Overlined variable indicates mean (over time) of variable, scaled (except in the case of $\beta_{j}$ ) by $V_{j, 1}$.

dPortfolios formed from 136 financial and non-financial firms.

negative association between inflation and stock returns. In fact, since only the effects linear in systematic risk are large in the aggregate, the evidence here is consistent with theories in which unexpected inflation does not cause aggregate stock price declines, but results from, or is spuriously correlated with, stock price declines [Fama (1981), Geske and Roll (1983)].

\section{Summary and conclusions}

This paper has shown that unexpected inflation has significantly different associations with stock returns for different firms/industries, and has provided 
a model to explain those differences. While some of the results of tests of that model vary according to the design, the following overall conclusions are supported.

Nominal contracting effects are of sufficient magnitude to be empirically detectable in stock price behavior. Thus, those effects appear to play a more important role in stock price behavior than could be inferred on the basis of previous research. Furthermore, the evidence casts doubt on the assertion that stock prices fail to reflect the gain to shareholders accruing from erosion in the real value of nominal corporate liabilities [Modigliani and Cohn (1979)].

The results also suggest that a large portion of the differential association of stock returns with unexpected inflation can be explained by differences in systematic risk. Such a finding would be expected if the differences among the associations of stock returns and unexpected inflation reflect differences in the reaction of stock prices to changes in real activity, which in turn, are correlated with unexpected inflation. Of all the factors examined, systematic risk is the most important in explaining differences in individual stock price behavior, and it is by far the most important in explaining aggregate stock price reaction to unexpected inflation. The effects of the other variables tend to be purely redistributive; they nearly offset in the aggregate.

Finally, the paper provides evidence that associations between unexpected inflation and operating profitability do differ across firms, and that there exists at least some stationarity in those differences. Underlying economic characteristics that could cause such differences were only briefly discussed, but empirical proxies for those characteristics were developed. In spite of the substantial measurement error likely to exist in those empirical proxies, they were capable of explaining a portion of the differential associations of stock returns with unexpected inflation. The evidence suggests that those who want to predict the reaction of individual stock prices to unexpected inflation should consider the economic characteristics of firms that would link operating profitability to unexpected inflation.

\section{Appendix A: Sample selection and measurement of firm-specific variables}

Firms in the sample were chosen primarily on the basis of data availability and to obtain 2 to 10 representatives from each of 27 industries, which are listed in table 2 . All sample firms except banks were required to have quarterly security market returns available on CRSP continuously from 1961 through 1980. In addition, annual income, tax expense, and depreciation from 1960 through 1980 and quarterly income or income before depreciation, interest, and taxes from 1965 through 1980 must have been disclosed on Compustat.

No banks had all the required CRSP and Compustat data. Therefore, banks listed on the CRSP tapes since 1969 were chosen. Security price data not available on CRSP were gathered from Barron's and Moody's Dividend 
Record. Accounting data not on Compustat were gathered from annual reports and 10-K's.

Thirty firms were excluded from the initial sample because information in annual reports concerning inventory was not sufficient to support a reliable estimate of real cash flows from operations, using the methods discussed below. Nine other firms were excluded from the sample because they experienced major shifts in lines of business. Those firms were eliminated because they were deemed unlikely to have stationary cash flow response parameters.

Selection of test periods was also a product of data availability. The procedures used to adjust operating income for inflation (see below) required information about inventory accounting methods, the content of inventory, and specific price indexes applicable to the inventory. None of this data was widely available prior to 1957 . A test period beginning in 1961 was selected and, in order to use the available price indexes, it was assumed that any inventory on hand in 1961 had been acquired no earlier than 1957.

Prior to 1966, the quarterly income statement data used to estimate cash flow response parameters were not widely available. The primary empirical tests are therefore restricted to the 1966-1980 period; quarterly data are used for both the measurement of security returns and the estimation of the cash flow response parameters. Supplemental tests use annual data from 1961-1980 for both the measurement of security returns and estimation of the cash flow response parameters. Within a given test, the measurement interval of the data was held constant in order to preserve the ability to evaluate the trade-off between a large sample size (with quarterly data) and reduced measurement error (in annual data), as discussed in section 3.1 .

\section{A.1. Measurement of real cash flows from operations}

Real (inflation-adjusted) cash flows from operations were approximated by current-cost operating income before depreciation, interest, and taxes. Since only historical-cost-based income was available over the test period chosen, current-cost operating income was estimated. This entailed restating cost of goods sold (excluding depreciation) on a replacement cost basis and then adjusting sales, cost of sales, and other operating expenses for changes in the general price level.

Restatement of cost of goods sold was carried out using methods similar to those of Falkenstein and Weil (1977). Inventory for each firm was matched with one or more of a list of over 1,000 specific price indexes, based upon descriptions of business found in annual reports, 10-K's, and Moody's Manuals. The inventory was then aged and restated on the basis of the change in the specific price index since date of purchase.

To assess the accuracy of the restatement procedure, the estimated amounts of cost of sales were compared to annual replacement cost disclosures required 
by the SEC in 1976-1979 and by the FASB in 1979-1980. The mean relative differences, as a fraction of the reported replacement cost of sales (excluding depreciation), was -0.0003 ; the mean absolute relative difference was 0.0070 . Thus, the restatement procedure appears quite accurate.

\section{A.2. Measurement of short-term and long-term monetary position}

The short-term monetary position was assumed equal to cash and short-term investments, minus current liabilities. Long-term monetary position was assumed equal to long-term monetary assets, minus long-term debt and preferred stock.

All data were available on the Compustat tapes except long-term monetary assets. Such monetary assets are not segregated from other long-term investments by Compustat. Where long-term investments exceeded 10 percent of total assets, details concerning the monetary portion of those investments were collected from annual reports. In addition, the monetary accounts of large, wholly-owned domestic unconsolidated subsidiaries were consolidated with the parents' accounts. Details on such subsidiaries were gathered from $10-\mathrm{K}$ reports if (according to Compustat) investments in all unconsolidated subsidiaries exceeded 10 percent of total assets and if (according to the $10-\mathrm{K}$ ) wholly-owned domestic unconsolidated subsidiaries accounted for more than 3 percent of total assets.

Until 1976, banks and other financial institutions were not required to provide data describing the maturity structure of investments in loans, leases, and mortgages. Therefore, the average fraction of those investments that were classified as short-term from 1976-1980 was assumed to apply to previous years also.

\section{A.3. Measurement of tax basis of depreciable assets}

The tax basis of depreciable assets was estimated by adjusting book values of plant, property, and equipment as disclosed in financial reports. Book values were first reduced by the investment in land and assets subject to percentagedepletion. (A depletion tax shield is not a fixed-dollar claim and thus is not a nominal contract.) The remaining book value was converted to a tax basis according to information about the firm's depreciation accounting methods, estimated average age of assets, and estimated useful life of assets. If a firm used straight-line depreciation for book purposes and accelerated depreciation for tax purposes, the adjustment procedure was

$$
\begin{aligned}
& \text { ESTIMATED TAX BASIS } \\
& =[G R O S S \text { BOOK VALUE }]\left[1-(R / L I F E)^{A G E}\right]
\end{aligned}
$$


where

$A G E=$ Accumulated depreciation $/$ Depreciation expense;

$L I F E=$ Gross book value $/$ Depreciation expense;

$R=$ Depreciation rate assumed for tax purposes. (For years prior to 1970 , when $200 \%$ declining balance methods were applied to nearly all assets, $R$ was equal to 2 . During the 1970 s, $R$ declined gradually to 1.8 as more conservative depreciation methods were phased in.)

The above adjustment procedure was modified in some years to consider changes in accounting methods and use of more than one depreciation method. When accelerated methods were used for both books and taxes, no adjustment was made.

\section{A.4. Measurement of systematic risk $(\beta)$}

Systematic risk was estimated using the market model. Estimates for periods in 1970 s were based on the 40 most recent quarterly observations. Estimates for the $1960 \mathrm{~s}$ were based on the 40 observations from 1960 through 1970 , excluding the year for which the estimate was used. (Data prior to 1960 were not available for many firms.)

\section{Appendix B: Measurement of unexpected inflation}

Inflation rates were measured using the Consumer Price Index. The unexpected component of inflation was assumed equal to the expected real rate of return of Treasury bills outstanding during the period, minus the actual real rate of return on those bills. Unexpected inflation was estimated for both quarterly and annual periods. Monthly data were not used because of concerns about error in the measurement of unexpected inflation over such a brief interval.

Nominal returns on 90-day Treasury bills and one-year Treasury notes were available on the CITIBANK tapes. Prior to the issue of one-year notes in 1963. estimated rates on one-year notes were developed by annualizing rates on 9-, 10-, or 11-month Treasury bills.

For tests based on quarterly data, expected real rates of return on Treasury bills were generated using a univariate model with moving average terms at lags 1,2 , and 4 . The models were re-estimated each month, generally using the 60 most recent quarterly observations. (Fewer than 60 observations were sometimes used in order to exclude data from the period prior to 1953, when interest rates were pegged.)

Expected annual real rates were developed by combining one-step-ahead through four-step-ahead forecasts of quarterly real rates, and then adding a constant liquidity risk premium. That constant premium was equal to the 
average excess of return on one-year Treasury bills over the return on threemonth Treasury bills for the 1960-1980 period.

The approach used to measure unexpected inflation is similar to that used by Fama and Gibbons (1984), but the time-series behavior of real interest rates was modeled somewhat differently, and the measures of unexpected real rates used here are based only on information available at the forecast date.

The accuracy and efficiency of the model used to forecast inflation was assessed using several methods. The accuracy of the quarterly forecasts, as measured by either the mean absolute error or the mean squared error, was superior to that of the Fama-Gibbons model, as estimated over the 1961-1980 period. (Annual forecasts were more accurate than the Fama-Gibbons model only in terms of mean absolute error.) Efficiency was assessed using Box-Pierce- $Q$ tests for autocorrelation in the forecast errors. The hypothesis of no autocorrelation (over 12 lags, for quarterly data, and 4 lags, for annual data) could not be rejected at any standard level of significance.

\section{Appendix C: Estimation of cash flow response parameters}

This appendix provides some details concerning the derivation of the method used to estimate the cash flow response parameters. The estimation procedure is based in part on eq. (6), which is rewritten below. The firm subscript $j$ has been dropped for convenience.

$$
\mathrm{E}_{t}\left(\tilde{C}_{\tau}\right)=\mathrm{E}_{t-1}\left(\tilde{C}_{\tau}\right)+\theta_{\tau-t+1} \tilde{u}_{t}+\tilde{z}_{t}^{\tau},
$$

where

$\tilde{C}_{\tau}=$ real cash flows from operations for period $\tau$,

$\tilde{u}_{t}=$ unexpected inflation of period $t$,

$\tilde{z}_{t}^{\tau}=$ portion of change in expected cash flows of period $\tau$ that is not correlated with unexpected inflation of period $t$.

Eq. (C.1) implies that

$$
\begin{aligned}
& \tilde{C}_{t}=\mathrm{E}_{t-1}\left(\tilde{C}_{t}\right)+\theta_{1} \tilde{u}_{t}+\tilde{z}_{t}^{t}, \\
& \mathrm{E}_{t-1}\left(\tilde{C}_{t}\right)=\mathrm{E}_{t-2}\left(\tilde{C}_{t}\right)+\theta_{2} \tilde{u}_{t-1}+\tilde{z}_{t-1}^{t}, \\
& \mathrm{E}_{t-2}\left(\tilde{C}_{t}\right)=\mathrm{E}_{t-3}\left(\tilde{C}_{t}\right)+\theta_{3} \tilde{u}_{t-2}+\tilde{z}_{t-2}^{t}, \\
& \mathrm{E}_{t-3}\left(\tilde{C}_{t}\right)=\mathrm{E}_{t-4}\left(\tilde{C}_{t}\right)+\theta_{4} \tilde{u}_{t-3}+\tilde{z}_{t-3}^{t},
\end{aligned}
$$

where all variables are as previously defined. 
One can then substitute (C.5) into (C.4), then (C.4) into (C.3), and (C.3) into (C.2). Eq. (C.6) below is the result of this series of substitutions:

$$
\tilde{C}_{t}=\mathrm{E}_{t-4}\left(\tilde{C}_{t}\right)+\theta_{1} \tilde{u}_{t}+\theta_{2} \tilde{u}_{t-1}+\theta_{3} \tilde{u}_{t-2}+\theta_{4} \tilde{u}_{t-3}+\tilde{v}_{t},
$$

where

$$
\tilde{v}_{t}=\tilde{z}_{t}^{t}+\tilde{z}_{t-1}^{t}+\tilde{z}_{t-2}^{t}+\tilde{z}_{t-3}^{t}
$$

We now note that eq. (4) in section 2.2 .2 implies that

$$
\mathrm{E}_{t-4}\left(\tilde{C}_{t}\right)=\tilde{C}_{t-4}+d
$$

Then (C.6) can be rewritten as

$$
\tilde{C}_{t}-\tilde{C}_{t-4}=d+\theta_{1} \tilde{u}_{t}+\theta_{2} \tilde{u}_{t-1}+\theta_{3} \tilde{u}_{t-2}+\theta_{4} \tilde{u}_{t-3}+\tilde{v}_{t}
$$

The method used to estimate the cash flow parameters, $\theta$, is described by eq. (C.8) below. (C.8) differs from (C.7) in that cash flows have been expressed on a per-share basis (adjusted for splits and stock dividends), to control the effect of growth through acquisitions and new stock issues:

$$
\left[\frac{\tilde{C}_{t}}{\tilde{S}_{t}}-\frac{\tilde{C}_{t-4}}{\tilde{S}_{t-4}}\right] \tilde{S}_{t-4}=d+\theta_{1} \tilde{u}_{t}+\theta_{2} \tilde{u}_{t-1}+\theta_{3} \tilde{u}_{t-2}+\theta_{4} \tilde{u}_{t-3}+\tilde{\varepsilon}_{t} .
$$

Eq. (C.8) is to be estimated with ordinary least squares. If the disturbance term $\tilde{\varepsilon}_{1}$ were serially correlated, some other estimation procedure would be more efficient. The likelihood of improving efficiency can be assessed through reference to the work of Foster (1977). Foster studied several alternative one-step-ahead forecasts of quarter $t$ earnings, including a naive forecast equal to earnings of quarter $t-4$, plus a drift term. The naive forecasts performed well, relative to other univariate forecasts, including those designed to yield forecast errors that are serially uncorrelated. Note that the dependent variable in eq. (C.8) is nearly equivalent to the forecast error (minus a constant) from Foster's naive model. Thus, even if the dependent variable in eq. (C.8) is serially correlated, attempts to model that correlation are unlikely to be successful. To the extent that the time series behavior of the dependent variable translates to the residuals, ordinary lcast squares cstimators should be as efficient as estimators that attempt to model serial correlation. 
In the supplemental tests based on annual data, eq. (C.8) is modified:

$$
\left[\frac{\tilde{C}_{t}}{\tilde{S}_{t}}-\frac{\tilde{C}_{t-2}}{\tilde{S}_{t-2}}\right] \tilde{S}_{t-2}=d+\theta_{1} \tilde{u}_{t}+\theta_{2} \tilde{u}_{t}+\tilde{\varepsilon}_{t} .
$$

The derivation assumes that as of the end of year $t-2$, expected annual income for year $t$ is equal to income of year $t-2$, plus a drift term.

\section{References}

Alchian, Arman A. and Reuben A. Kessel, 1959, Redistribution of wealth through inflation, Science 130 , no. 3375, 535-539.

Bach, G.L. and James B. Stephenson, 1974, Inflation and the redistribution of wealth, Review of Economics and Statistics 56, 1-13.

Bernard, Victor L., 1984. The use of market data and accounting data in hedging against consumer price inflation, Journal of Accounting Research 22, 445-466.

Bradford. William, 1974, Inflation and the value of the firm, Southern Economic Journal 40, 414-427.

Dietrich, J. Richard, 1981, Recognition and measurement of gains and losses on long-term debt in periods of inflation: An empirical study of security returns, $\mathrm{Ph} . \mathrm{D}$. dissertation (Carnegie-Mellon University, Pittsburgh, PA).

Falkenstein, Angela and Roman Weil, 1977, Replacement cost accounting: What will income statements based on the SEC disclosures show?, Financial Analysts Journal, Jan./Feb., 46-57, March/April, 48-57.

Fama, Eugene F., 1981, Stock returns, real activity, inflation, and money, American Economic Review 71, 545-565.

Fama, Eugene F. and Michael Gibbons, 1984, A comparison of inflation forecasts, Journal of Monetary Economics 13, 327-348.

Fama, Eugene F. and G. William Schwert, 1977, Asset returns and inflation, Journal of Financial Economics 5, 115-146.

Feldstein, Martin, Jerry Green and Eytan Sheshinski, 1978, Inflation and taxes in a growing economy with debt and equity finance, Journal of Political Economy 86, part II, S53-S70.

Feldstein. Martin and Lawrence Summers, 1979, Inflation and the taxation of capital income in the corporate sector, National Tax Journal 32, 445-470.

Flannery, Mark J. and Christopher James, 1984, The effect of interest rate changes on the common stock returns of financial institutions, Journal of Finance 39, 1141-1154.

Foster, George, 1977, Quarterly accounting data: Time series properties and predictive-ability results, The Accounting Review 52, 1-22.

French, Kenneth, Richard Ruback and G. William Schwert, 1983, Effects of nominal contracting on stock returns, Journal of Political Economy 91, 7-97.

Geske, Robert and Richard Roll, 1983, The fiscal and monetary linkage between stock returns and inflation, Journal of Finance 38, 1-33.

Hamada, Robert S., 1969, Portfolio analysis, market equilibrium and corporate finance, Journal of Finance 24, 13-31.

Hong. Hai, 1977, Inflation and the market value of the firm: Theory and tests, Journal of Finance $32,1031-1048$.

Judge, George G., William E. Griffiths, R. Carter Hill and Tsoung-Chao Lee, 1980, The theory and practice of econometrics (Wilcy, New York).

Keynes, John Maynard, 1924, Monetary reform (Harcourt, Brace and Company, New York).

Madalla, G. S., 1977, Econometrics (McGraw-Hill, New York).

Mandelker, Gershon and S. Ghon Rhee, 1981, Redistribution of wealth through inflation: A re-examination of the Fisher-Kevnes-Kessel hypothesis, Manuscript (University of Pittsburgh. Pittsburgh, PA). 
Modigliani, Franco and Richard A. Cohn, 1979, Inflation, rational valuation, and the market, Financial Analysts Journal, March/April, 24-44.

Okun, Arthur M., 1981, Prices and quantities: A macroeconomic analysis (The Brookings Institution, Washington, DC).

Schipper, Katherine and Rex Thompson, 1981, Common stocks and hedges against shifts in the consumption or investment opportunity set, Journal of Business 54, 305-328.

Summers, Lawrence, 1981, Inflation and the valuation of corporate equities, National Bureau of Economics Research working paper no. 824.

Theil, Henri, 1971, Principles of econometrics (Wiley, New York). 